\title{
Synthesis and Characterization of Poly(D,L-Lactide-co-Glycolide) Copolymer
}

\author{
Cynthia D’Avila Carvalho Erbetta ${ }^{1}$, Ricardo José Alves ${ }^{2}$, Jarbas Magalhães Resende ${ }^{3}$, \\ Roberto Fernando de Souza Freitas ${ }^{1}$, Ricardo Geraldo de Sousa ${ }^{{ }^{*}}$
}

${ }^{1}$ Polymer Science and Technology Laboratory, Chemical Engineering Department, School of Engineering, Federal University of Minas Gerais, Belo Horizonte, Brazil; ${ }^{2}$ Pharmaceutical Products Department, Pharmacy School, Federal University of Minas Gerais, Belo Horizonte, Brazil; ${ }^{3}$ Chemical Department, Exact Sciences Institute, Federal University of Minas Gerais, Belo Horizonte, Brazil. Email: *sousarg@ufmg.br

Received January $12^{\text {th }}, 2012$; revised February $25^{\text {th }}, 2012$; accepted March $14^{\text {th }}, 2012$

\begin{abstract}
The copolymer poly(D,L-lactide-co-glycolide) is one of the most interesting polymers for medical applications. This interest is justified by the fact that it is bioreabsorbable, biocompatible and non-toxic, while its degradation kinetics can be modified by the copolymerization ratio of the monomers. In this study, copolymers were synthesised at $175^{\circ} \mathrm{C}$ by opening the rings of the cyclic dimers of the D,L-lactide and glycolide monomers in the presence of stannous octoate initiator and lauryl alcohol co-initiator. The application of vacuum to the reaction medium, coupled with adequate stirring, is essential for obtaining good results. The following analytical techniques were used to characterise the synthesised copolymers: Differential Scanning Calorimetry (DSC), Thermogravimetry (TG), Nuclear Magnetic Resonance Spectroscopy (NMR) and Fourier Transform Infrared Spectroscopy (FTIR). Both the input monomers and the reaction products were analysed. Important characteristics, such as melting temperature, glass transition temperature, thermal stability, chemical composition and the ratio of the monomers in the synthesised copolymer, were obtained from these analyses. These results helped to infer the absence of residual monomers in the synthesised copolymers.
\end{abstract}

Keywords: PLGA; Synthesis; Characterization; DSC; TG; NMR; FTIR

\section{Introduction}

The most important components of a living cell (proteins, carbohydrates and nucleic acids) are all polymers. Nature uses polymers for construction and as part of the complicated cellular mechanisms [1]. Polymers are a very versatile class of materials and have been changing our daily lives for decades [2] with important applications in the areas of medicine [3,4], agriculture [5,6], and engineering [7].

There has been a rapid growth in the medical use of polymeric materials in many fields including tissue engineering, implant of medical devices and artificial organs, prostheses, ophthalmology, dentistry, and bone re- pair [8-11].

The polyesters poly(lactic acid) (PLA) and poly(glycolic acid) (PGA) were the two first materials to be successfully used as sutures, and these polymers have extensively been used over the past two decades [12]. These polymers have widespread pharmaceutical use. They belong to a group of polymers that carry hydrolysable groups within their [5], which are susceptible to biodegradation [13]. An interesting alternative to the use of these materials is the copolymer poly(D,L-lactide-co-glycolide) (PLGA), which contains alternate unities of lactic acid and glycolic acid monomers. The structures of PGA, PLA and PLGA are presented in Figure 1.<smiles>COCC=O</smiles>

(a)<smiles>COC(C)C1CC1(C)OC</smiles>

(b)<smiles>COCC(=O)OC(C)C(C)=O</smiles>

(c)

Figure 1. Polymers with hydrolysable chains: (a) Poly(glycolic acid); (b) Poly(lactic acid) and (c) Poly(D,L-lactide-coglycolide) copolymer.

"Corresponding author. 
PLA and PLGA are relatively hydrophobic polyesters, unstable in damp conditions and biodegradable to nontoxic by-products (lactic acid, glycolic acid, carbon dioxide, and water).

The polymers derived from lactic and glycolic acids have received a great deal of attention in research on alternative biodegradable polymers. Various studies demonstrating their low toxicity, including their approval by the Food and Drug Administration (FDA) for use as drug delivery systems (DDS) can be found in the literature [14,15]. PLGA copolymers have desirable properties, such as a constant biodegradation rate, mechanical resistance, and regular individual chain geometry $[10,16,17]$.

The copolymerization of PLGA can basically be done in two ways: 1) Through a direct polycondensation reaction of lactic acid and glycolic acid, resulting in copolymers of low molecular weight $[18,19]$; 2) Through an opening polymerization of cyclic dimers of lactic acid (lactide) and glycolic acid (glycolide), resulting in copolymers with high molecular weight and therefore with better mechanical properties [20-23]. The bulk polymerization generally takes from two to six hours for temperatures around $175^{\circ} \mathrm{C}$ and in the presence of initiator. Lauryl alcohol can be added during the process in order to control the molecular weight [8].

Lactide is more hydrophobic than glycolide, therefore PLGA copolymers rich in lactide are less hydrophilic and absorb less water, leading to a slower degradation of the polymer chains [10]. It is important to stress that the ratio glycolide to lactide and the physical-chemical properties of the corresponding copolymer are not linear. While PGA is highly crystalline, the crystallinity rapidly disappears in copolymers of lactide and glycolide. This morphological change leads to an increase in the rate of hydration and hydrolysis [24]. According to GILDING and REED (1979) [20], the greater reactivity of glycolide compared to lactide means that glycolide is usually found in the final polymer in a greater proportion compared to its portion in the initial mixture of monomers.

The mechanical properties, the capacity for hydrolysis and the degradation velocity of these polymers may be all influenced by the molecular mass and the degree of crystallinity $[25,26]$. The degradation period of biodegradable polymers is most significantly affected by: the chemical structure and composition of the system; the molecular mass distribution of the polymers; the presence of monomers and oligomers; the size and shape of the system surface; the morphology of the system components and the hydrolysis mechanism [27].

Lactide has asymmetric carbons, which means that the levorotatory (L-PLA), dextrorotatory (D-PLA) and racemic (D,L-PLA) polymeric forms may be obtained. The levorotatory and dextrorotatory forms are semi-crystalline, while the racemic form is amorphous due to the irregularities in the polymer chain [28]. The use of (D,LPLA) is preferred in a DDS system, as the drug can be more homogeneously distributed through the polymer matrix [29]. When polymers are produced for medical applications, two tin salts, tin (II) chloride and tin (II) 2ethylhexanoate, abbreviated to Stannous Octoate [Sn(Oct $)_{2}$ ], may be used as polymerization catalysts [21].

The main objective of this study regards the synthesis of one of the most widely used biopolymers in the medical area, the copolymer poly(D,L-lactide-co-glycolide). New conditions suitable for its synthesis are explored. The obtained biopolymers were characterised by using a variety of analytical techniques in order to identify their chemical composition, as well as the final ratio between monomers within the polymeric structure. Analytical techniques have also been employed in order to investigate the biopolymers thermal behaviour as well as to verify the presence or absence of unreacted monomers in the final reaction mixture.

\section{Materials and Methods}

\subsection{PLGA Copolymer Synthesis}

PLGA was synthesised by opening the rings of D,L-lactide and glycolide in a mass polymerization. Variables such as the proportion of the stannous octoate initiator ( $0.02 \%$ of the total monomer mass) and the lauryl alcohol co-initiator $(0.01 \%$ of the total monomer mass) were chosen based on the study conducted by KIREMITÇIGÜMÜSDERELIOGLU and DENIZ (1999) [30]. Other process variable reference values, such as the reaction time $(2 \mathrm{~h})$ and temperature $\left(175^{\circ} \mathrm{C}\right)$ were chosen according to a previous study by BENDIX (1998) [21]. The copolymerization reaction is illustrated in Figure 2 [30].

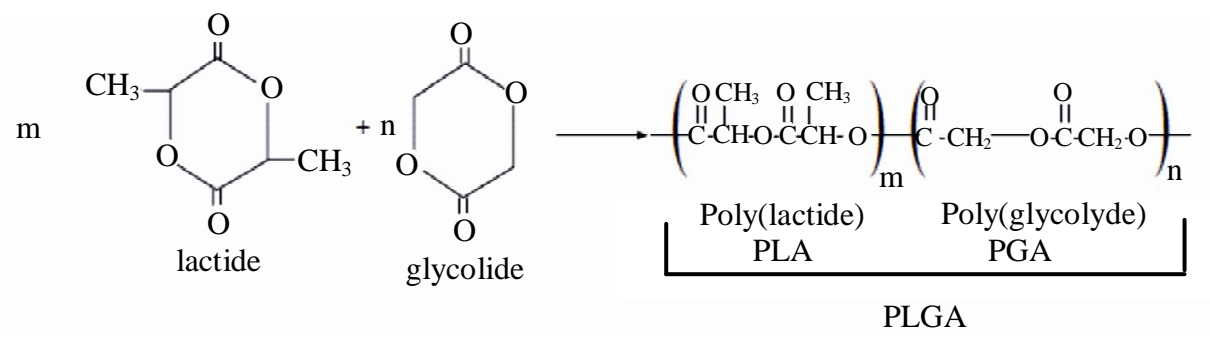

Figure 2. Chemical structure of the dimers and polymers, and the copolymerization reaction. 
Monomer ratios of 70/30 and 50/50 (D,L-lactide/glycolide) have been used in the syntheses. These proportions have been chosen by considering the degradation time of these copolymers [8]. These are the most commonly used ratios in controlled drug delivery systems.

A total of eight syntheses have been performed, with four of these using the 70/30 ratio and the other four with the 50/50 ratio. The synthesis methodology has been modified in order to optimize the process. In the first two syntheses (syntheses 1 and 2) a round-bottomed flask without a stopper has been used. The reagents were added to the flask, which was immersed in a thermostatic bath (Haake/B12) and stirred during the first 10min of the synthesis. In synthesis 3 a rotary evaporator (Technical/TE-210) was employed. The only difference between this and preceding reaction was the injection of nitrogen into the reaction medium. In synthesis 4 , the round-bottomed flask was replaced by vacuometer-type glass flask (Protec), allowing a high vacuum $(-60 \mathrm{cmHg})$ to be applied and controlled. Mechanical stirring was used throughout the synthesis. From this synthesis onwards, nitrogen was no longer injected into the reaction medium. Hence, in the last four syntheses (syntheses 5 to 8 ), a glass flask with a rubber stopper was used instead of the vacuometer flask and the vacuum was achieved after all of the synthesis reagents had been added. Magnetic stir- ring was continued until the magnetic bar ceased to move due to the increased viscosity of the solution. Table 1 summarises the syntheses carried out. They are allocated to groups characterising the 4 different routes (group), as described above.

At the end of the syntheses, the PLGA copolymer was dissolved in anhydrous methylene chloride and precipitated in excess anhydrous methanol. The obtained material was dried at between $60^{\circ} \mathrm{C}$ and $70^{\circ} \mathrm{C}$ under vacuum $(-60 \mathrm{cmHg})$ in an oven (Vacuoterm/6030A) for a minimum of $48 \mathrm{~h}$ to remove residual solvents. The copolymer was then ground using a ball mill (Stoneware) at $100 \mathrm{rpm}$ for at least $24 \mathrm{~h}$. The ground PLGA was sieved in a 24mesh sieve.

\subsection{PLGA Copolymer Characterization}

\subsubsection{Differential Scanning Calorimetry (DSC)}

The DSC equipment used, a Shimadzu model DSC-50, was programmed to first heat the samples from room temperature $\left( \pm 20^{\circ} \mathrm{C}\right)$ to $120^{\circ} \mathrm{C}$ at a rate of $10^{\circ} \mathrm{C} \cdot \mathrm{min}^{-1}\left(1^{\mathrm{st}}\right.$ run). All PLGA samples were subjected to this first run to eliminate the material's thermal history. An unsealed aluminium sample vessel was used with nitrogen as the carrier gas at a flow rate of $20 \mathrm{~mL} \cdot \mathrm{min}^{-1}$. The mass of the analysed sample varied from 5 to $10 \mathrm{mg}$. At the end of the first run, the oven was cooled with liquid nitrogen until it reached a temperature of between $-20^{\circ} \mathrm{C}$ and $-30^{\circ} \mathrm{C}$. The equipment was then programmed for another run up to $300^{\circ} \mathrm{C}$, at a heating rate of $10^{\circ} \mathrm{C} \cdot \mathrm{min}^{-1}$ for the monomers and $5^{\circ} \mathrm{C} \cdot \mathrm{min}^{-1}$ for the copolymers. The second-run DSC curve was the reference for determining the glass transition temperature $\left(\mathrm{T}_{\mathrm{g}}\right)$, phase transition temperature $\left(T_{m}\right)$, and degradation temperature $\left(T_{d}\right)$.

\subsubsection{Thermogravimetry (TG)}

TG analysis was carried out to measure change in mass with increase in temperature, thermal stability, and maximum degradation temperature for the samples. The test was conducted at a heating rate of $10^{\circ} \mathrm{C} \cdot \mathrm{min}^{-1}$ from room temperature $\left( \pm 20^{\circ} \mathrm{C}\right)$ to $400^{\circ} \mathrm{C}$ in an unsealed platinum sample vessel under nitrogen atmosphere with a flow rate of $20 \mathrm{~mL} \cdot \mathrm{min}^{-1}$. The equipment used was a Shimadzu model TGA-50. The mass of the analysed samples varied between 5 and $10 \mathrm{mg}$. This technique allowed us to determine the temperature at which thermal degradation commenced $\left(\mathrm{T}_{\text {onset }}\right)$ and the change in mass as a function of temperature increase. Derived thermogravimetric curves (DrTG) were used to identify the maximum degradation temperature $\left(\mathrm{T}_{\text {deg.max. }}\right)$.

Table 1. Syntheses by group.

\begin{tabular}{|c|c|c|c|c|c|c|c|}
\hline GROUP & SYNTHESIS & $\begin{array}{l}\text { LA/GL } \\
(\%)\end{array}$ & $\begin{array}{c}\text { TOTAL MONOMER } \\
\text { MASS (g) }\end{array}$ & $\begin{array}{l}\text { LACTIDE } \\
\text { MASS (g) }\end{array}$ & $\begin{array}{l}\text { GLYCOLIDE } \\
\text { MASS (g) }\end{array}$ & $\begin{array}{l}\text { STANNOUS OCTOATE } \\
\text { VOLUME }(\mu \mathrm{L})\end{array}$ & $\begin{array}{l}\text { LAURYL ALCOHOL } \\
\text { VOLUME }(\mu \mathrm{L})\end{array}$ \\
\hline \multirow{2}{*}{ I } & 1 & $70 / 30$ & 17 & 11.9029 & 5.1006 & 2.72 & 2.06 \\
\hline & 2 & $50 / 50$ & 17 & 8.5043 & 8.5016 & 2.72 & 2.06 \\
\hline II & 3 & $70 / 30$ & 17 & 11.9050 & 5.1091 & 2.72 & 2.06 \\
\hline III & 4 & $50 / 50$ & 51 & 25.5067 & 25.5107 & 8.16 & 6.18 \\
\hline \multirow{4}{*}{ IV } & 5 & $50 / 50$ & 17 & 8.5078 & 8.5054 & 2.72 & 2.06 \\
\hline & 6 & $50 / 50$ & 17 & 8.5053 & 8.5035 & 2.72 & 2.06 \\
\hline & 7 & $70 / 30$ & 17 & 11.9104 & 5.1094 & 2.72 & 2.06 \\
\hline & 8 & $70 / 30$ & 17 & 11.9049 & 5.1024 & 2.72 & 2.06 \\
\hline
\end{tabular}




\subsubsection{Fourier Transform Infrared (FTIR)}

The infrared absorption spectra were collected at $20^{\circ} \mathrm{C}$ from $4000-650 \mathrm{~cm}^{-1}$ for monomers and copolymers samples. The spectra were recorded on a Perkin Elmer spectrometer operating in the ATR (Attenuated Total Reflectance) mode. 4 scans have been performed for a resolution of $4 \mathrm{~cm}^{-1}$. The FTIR analyses of several samples containing mixtures of PLGA and monomers have also been carried out to investigate the presence of residual monomers in the PLGA copolymers.

\subsubsection{Nuclear Magnetic Resonance (NMR)}

NMR samples have been prepared by dissolving the copolymers in $\mathrm{CDCl}_{3}$ from Aldrich containing TMS at $0.05 \%$. ${ }^{1} \mathrm{H}$ and ${ }^{13} \mathrm{C}$ NMR spectra were obtained at, respectively, $400 \mathrm{MHz}$ and $100 \mathrm{MHz}$. Measurements have been performed at $300 \mathrm{~K}$ on a Bruker AVANCE DRX 400 spectrometer equipped with a ${ }^{1} \mathrm{H}_{-}{ }^{13} \mathrm{C} 5 \mathrm{~mm}$ dual probe. The ${ }^{1} \mathrm{H}$ NMR spectra were used to determine the ratio of the monomers in the analysed copolymers. In some cases quantitative ${ }^{13} \mathrm{C}$ spectra have been obtained by using inverse-gated decoupling, in order to confirm the results obtained from ${ }^{1} \mathrm{H}$ NMR spectroscopy. TMS was used as internal reference.

\section{Results and Discussion}

\subsection{Synthesis of the PLGA Copolymers}

During the first two syntheses (1 and 2) it was noted that vapour formed, partially condensed on the wall of the reaction flask, and then crystallised after cooling naturally. In seeking the most favourable copolymerization conditions, rotary vapour equipment was used in synthesis 3. This also enabled nitrogen to be injected, with a vacuum pump providing suction. However, the formation of vapour became more pronounced and intense. Some of the crystals were removed for analysis to identify their composition and, consequently, to define a more appropriate synthesis route.

It is possible to conclude from DSC, TG, and FTIR analyses of the crystals obtained in synthesis 3 that they were produced from the evaporation and crystallisation of the D,L-lactide monomer. Because of this, vacuum was applied in the subsequent syntheses without injection of nitrogen, by using sealed glass flasks.

Glycolide melted during the first minutes of the reaction and occupied the lower part of the reaction flask, while the other monomer, D,L-lactide, needed more time to melt and was suspended in the molten glycolide until its complete melt. Accordingly, efficient stirring was required to avoid preferential polymerization of the glycolide or the formation of a block of copolymer, as favoured by the following conditions: the temperature, the greater reactivity of glycolide compared with D,L-lactide, and the presence of the initiator. Another important synthesis variable is the application of vacuum, since it avoids the presence of moisture-which is extremely harmful to the copolymerization process [8,31,21] - and high pressure in the system due to evaporation of $D$, L-lactide monomer. With the evaporation of D,L-lactide the pressure inside the reaction flask (closed system) increases, favouring its condensation back to the reaction flask.

It was noted that copolymers with a greater proportion of glycolide are less soluble, requiring a greater volume of solvent (anhydrous methylene chloride) and more time for complete dissolution.

\subsection{Characterization of the Monomers and PLGA Copolymers}

\subsubsection{Differential Scanning Calorimetry (DSC)}

Figure 3 shows the DSC curves for the second heating in the thermal study of the analysed monomers. The DSC curves show how heat (mW) varies as a function of temperature. Both curves show two sharp endothermic events.

It can be seen from Figure 3 that the first thermal event on the DSC curves represents the melting of the monomers $\left(81^{\circ} \mathrm{C}\right.$ for glycolide and $125^{\circ} \mathrm{C}$ for D,L-lactide). For D,L-lactide, the second endothermic peak (at $183^{\circ} \mathrm{C}$ ) characterises the evaporation of this monomer, also identified in the monomer characterization conducted by JABBARI and XUEZHONG (2008) [32]. In the case of glycolide, the second peak (at $206^{\circ} \mathrm{C}$ ) relates to the degradation of the monomer, since glycolide does not have a boiling point.

Figures $\mathbf{4}$ and $\mathbf{5}$ give DSC curves for the synthesised copolymers, grouped in accordance with the ratio of monomers. It can be seen that the thermal behaviour of the biopolymers is very similar, which means that all of them have a glass transition phase between $31^{\circ} \mathrm{C}$ and $53^{\circ} \mathrm{C}$

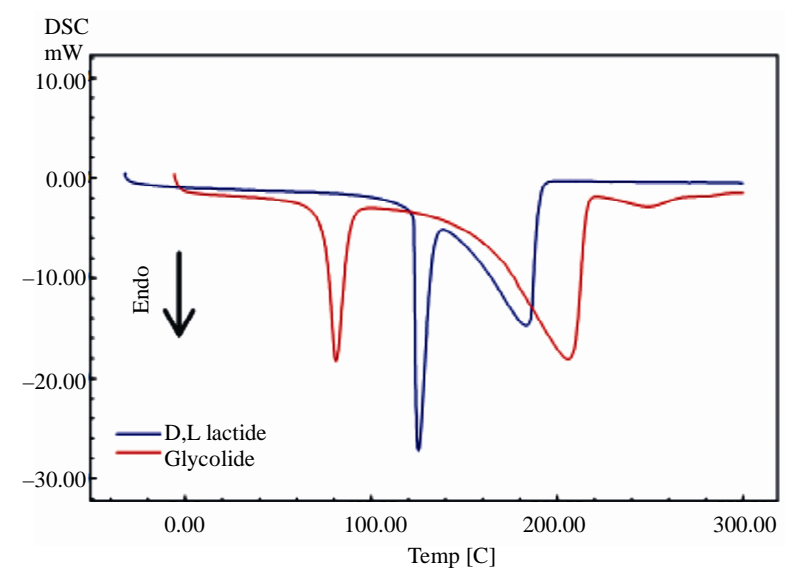

Figure 3. DSC curves of D,L-lactide and glycolide monomers (2nd heating). Heating rate of $10^{\circ} \mathrm{C} \cdot \mathrm{min}^{-1}$ and heating to $300^{\circ} \mathrm{C}$. 


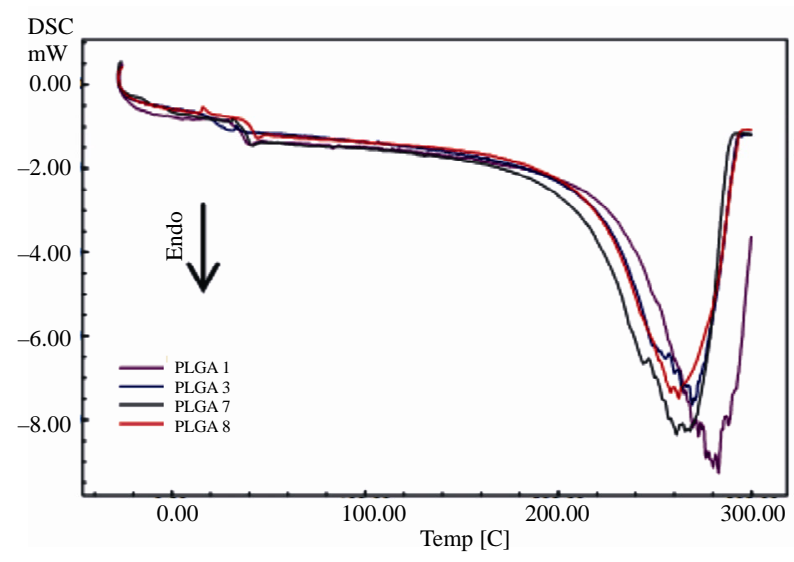

Figure 4. DSC curves of PLGA 70/30 copolymers (syntheses $1,3,7$, and 8 ), 2nd heating. Heating rate of $5^{\circ} \mathrm{C} \cdot \mathrm{min}^{-1}$ from $-25^{\circ} \mathrm{C}$ to $300^{\circ} \mathrm{C}$.

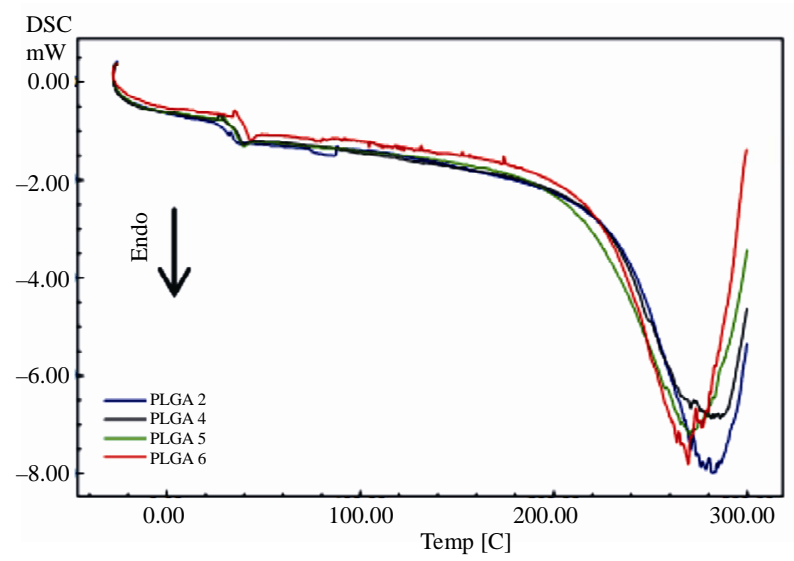

Figure 5. DSC curves of PLGA 50/50 copolymers (syntheses $2,4,5$, and 6 ), 2nd heating. Heating rate of $5^{\circ} \mathrm{C} \cdot \mathrm{min}^{-1}$ from $-25^{\circ} \mathrm{C}$ to $300^{\circ} \mathrm{C}$.

and degrade above $200^{\circ} \mathrm{C}$. From these DSC curves, it is possible to see the thermal transitions related to the glass transition (change in the angle of the DSC curves to the baseline) and the degradation of the polymeric chains (endothermic peak of the DSC curves).

The absence of a melting transition phase event can also be seen from the analysis of these curves. It can be inferred that all of the analysed copolymers are amorphous, which is in agreement with the literature. PLGAs containing less than $85 \%$ glycolide are amorphous [33]. Comparing the DSC curves in Figures $\mathbf{4}$ and $\mathbf{5}$ with that of Figure 3, it can be seen that there is no indication of residual monomers in the synthesised copolymers, since no endothermic event characteristic of theses monomers melting is observed on the respective DSC curves.

The results of the DSC analyses are summarised in Table 2. This table gives the glass transition $\left(T_{g}\right)$ and degradation $\left(T_{d}\right)$ temperatures for the PLGA copolymers. The melting $\left(\mathrm{T}_{\mathrm{m}}\right)$, boiling and/or degradation tempera-
Table 2. Thermal properties of the monomers and copolymers obtained by DSC.

\begin{tabular}{cccc}
\hline SAMPLE & $\mathbf{T}_{\mathrm{g}}\left({ }^{\circ} \mathbf{C}\right)$ & $\mathbf{T}_{\mathrm{m}}\left({ }^{\circ} \mathrm{C}\right)$ & $\mathbf{T}_{\mathbf{d}}\left({ }^{\circ} \mathrm{C}\right)$ \\
\hline D,L lactide & N/A & 125 & $183^{*}$ \\
Glycolide & N/A & 81 & 206 \\
PLGA 70/30 synthesis 1 & 46 & N/A & 283 \\
PLGA 50/50 synthesis 2 & 31 & N/A & 282 \\
PLGA 70/30 synthesis 3 & 53 & N/A & 269 \\
PLGA 50/50 synthesis 4 & 35 & N/A & 282 \\
PLGA 50/50 synthesis 5 & 35 & N/A & 270 \\
PLGA 50/50 synthesis 6 & 40 & N/A & 270 \\
PLGA 70/30 synthesis 7 & 38 & N/A & 261 \\
PLGA 70/30 synthesis 8 & 39 & N/A & 262 \\
\hline
\end{tabular}

* refers to the D,L-lactide monomer evaporation and not its degradation; N/A $=$ Not applicable.

tures are given for the monomers. All of the values were determined by the equipment software. The $T_{d}$ and $T_{m}$ values relate to the endothermic peaks of the DSC curves.

After the synthesis variables were standardised, syntheses 5 and 6 for the PLGA 50/50 and 7 and 8 for PLGA $70 / 30$ had very good repeatability for the polymerization product. The $T_{g}$ and $T_{d}$ values for these biopolymers, obtained from duplicate syntheses, are identical or very close. This indicates the same thermal behaviour and, therefore, similar structures and morphologies for the two biopolymers synthesised in different batches.

The degradation temperature of PLGA $70 / 30\left(261.5^{\circ} \mathrm{C}\right.$ $\pm 0.5^{\circ} \mathrm{C}$; related to the syntheses 7 and 8 ) is lower than that of PLGA $50 / 50\left(270^{\circ} \mathrm{C}\right.$; related to the syntheses 5 and 6). A greater quantity of the D,L-lactide monomer in the PLGA induces a greater branching in the structure due to the presence of the methyl group, making it stereochemically less thermostable. This means that the structure of PLGA 70/30 is more susceptible to thermal degradation than that of PLGA 50/50, thus giving a lower $T_{d}$. When the curves obtained in the present study (Figure 5) are compared with the DSC curves for the D,L-PLGA copolymer published by SILVA JUNIOR and collaborators (2009) [34] the same behaviour regarding the glass transition and degradation of the biopolymers is observed. The values found for these temperatures are lower than the respective values found in the literature [34], possibly due to the fact that the obtained polymers have lower molecular masses, something that was not determined experimentally. Polymers with lower molecular masses degrade more easily than those with higher molecular masses [35].

\subsubsection{Thermogravimetry (TG)}

Figures 6 to 8 show the thermogravimetry curves (TG or TGA) and their derivatives obtained for the D,L-lactide 


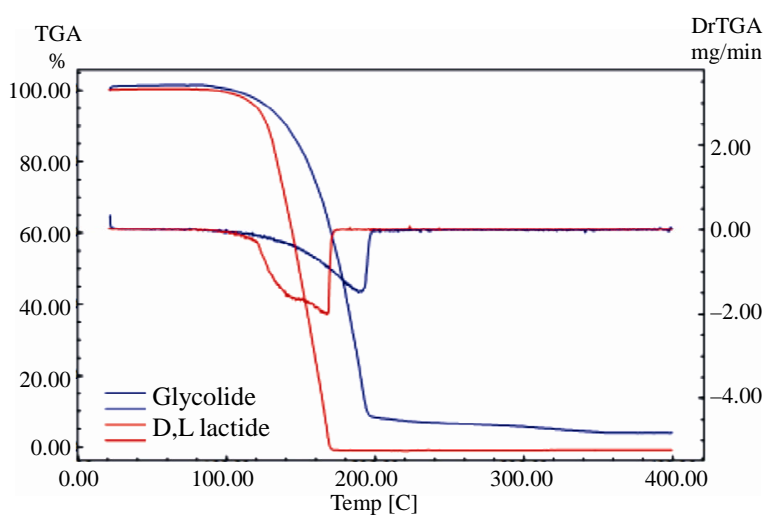

Figure 6. TG and DrTG curves of glycolide and D,L-lactide monomers. Heating rate of $10^{\circ} \mathrm{C} \cdot \mathrm{min}^{-1}$ from room temperature to $400^{\circ} \mathrm{C}$.

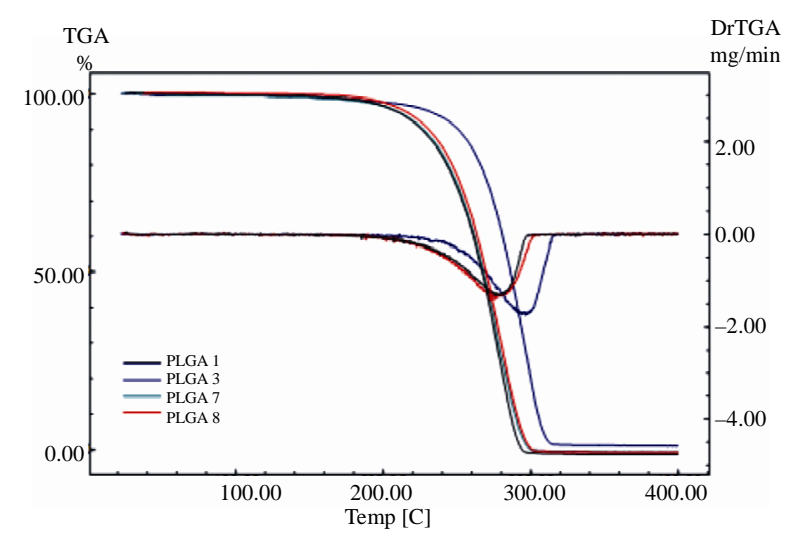

Figure 7. TG and DrTG curves of PLGA 70/30 copolymers (syntheses $1,3,7$, and 8 ). Heating rate of $10^{\circ} \mathrm{C} \cdot \mathrm{min}^{-1}$ from room temperature to $400^{\circ} \mathrm{C}$.

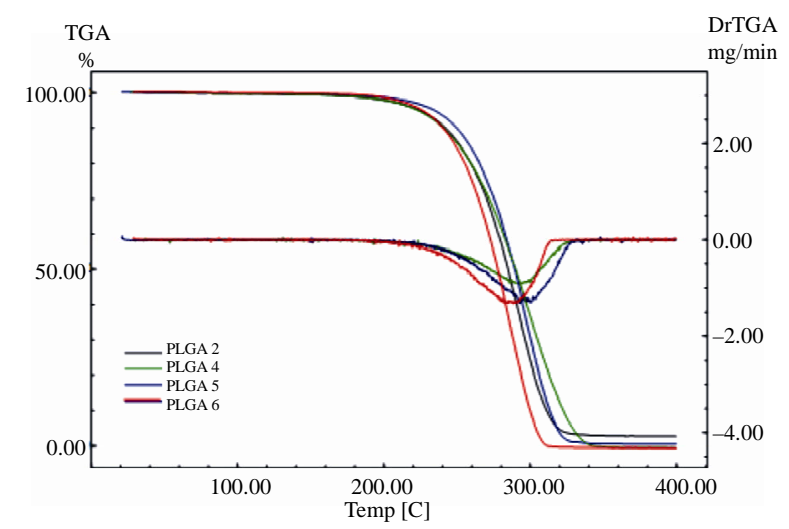

Figure 8. TG and DrTG curves of PLGA 50/50 copolymers (syntheses $2,4,5$, and 6 ). Heating rate of $10^{\circ} \mathrm{C} \cdot \mathrm{min}^{-1}$ from room temperature to $400^{\circ} \mathrm{C}$.

and glycolide monomers and for the synthesised copolymers. These curves show the variation of mass (\%) and the derivative of the mass loss (DrTG or DrTGA) as a function of temperature $\left({ }^{\circ} \mathrm{C}\right)$. All of the TG curves presented in these figures show a single mass loss event related to the degradation process, except for the D,Llactide monomer, in which this thermal event related to its evaporation is observed.

The results from the TG analyses for the monomers and copolymers are presented in Table 3. The $\mathrm{T}_{\text {onset }}$ and $\mathrm{T}_{\text {endset }}$ values (respectively, the temperatures at which mass loss begins and ends) were obtained from the TG curves, along with the results for $\mathrm{T}_{\text {deg.max. }}$ (temperature of maximum mass loss) for the DrTG curves of the respecttive monomers and copolymers.

The existence of only one mass loss stage for the copolymers is confirmed by the single peak observed in the DrTG curves. The copolymers fully degraded $(100 \%$ mass loss), except PLGA 50/50 obtained from synthesis 4, which was 99\%, and for PLGA 50/50 obtained by synthesis 2 , which was $97 \%$. This same mass loss value was observed for the degradation of the glycolide monomer. The thermogravimetry results presented above indicate that the degradation onset temperatures $\left(\mathrm{T}_{\text {onset }}\right)$ of the synthesised copolymers are higher than $240^{\circ} \mathrm{C}$.

The closeness between the respective values of $T_{\text {onset }}$ and $\mathrm{T}_{\text {deg.max. }}$ for PLGA 50/50 obtained from syntheses 5 and 6, and for PLGA 70/30 obtained from syntheses 7 and 8 , also indicates the good repeatability of these methodologies. This was achieved through the standardisation of variables carried out during the copolymer synthesis stage. In addition, it can be seen that these temperatures were lower for PLGA 70/30 than for PLGA 50/50, similar to the $T_{d}$ values observed for these copolymers using DSC. By comparing the $\mathrm{T}_{\text {deg.max. }}$ values

Table 3. Thermal properties of monomers and copolymers obtained by TG.

\begin{tabular}{ccccc}
\hline SAMPLE & $\begin{array}{c}\text { MASS } \\
\text { LOSS (\%) }\end{array}$ & $\mathbf{T}_{\text {onset }}\left({ }^{\circ} \mathrm{C}\right)$ & $\mathbf{T}_{\text {deg.max. }}\left({ }^{\circ} \mathrm{C}\right)$ & $\mathbf{T}_{\text {endset }}\left({ }^{\circ} \mathrm{C}\right)$ \\
\hline D,L lactide & 100 & 137 & $168^{*}$ & 169 \\
Glycolide & 97 & 161 & 189 & 195 \\
$\begin{array}{c}\text { PLGA 70/30 } \\
\text { synthesis 1 }\end{array}$ & 100 & 265 & 296 & 307 \\
$\begin{array}{c}\text { PLGA 50/50 } \\
\text { synthesis 2 }\end{array}$ & 97 & 257 & 293 & 312 \\
$\begin{array}{c}\text { PLGA 70/30 } \\
\text { synthesis 3 }\end{array}$ & 100 & 241 & 273 & 295 \\
$\begin{array}{c}\text { PLGA 50/50 } \\
\text { synthesis 4 }\end{array}$ & 99 & 264 & 293 & 314 \\
$\begin{array}{c}\text { PLGA 50/50 } \\
\text { synthesis 5 }\end{array}$ & 100 & 252 & 299 & 326 \\
$\begin{array}{c}\text { PLGA 50/50 } \\
\text { synthesis 6 }\end{array}$ & 100 & 248 & 289 & 305 \\
$\begin{array}{c}\text { PLGA 70/30 } \\
\text { synthesis 7 }\end{array}$ & 100 & 245 & 276 & 290 \\
$\begin{array}{c}\text { PLGA 70/30 } \\
\text { synthesis 8 }\end{array}$ & 100 & 245 & 279 & 295 \\
\hline relates to evaporation. & & &
\end{tabular}

*'relates to evaporation. 
obtained from the DrTG curves of the copolymers with the $T_{d}$ values determined from the DSC curves (Table 2), it can be seen that they are between $261^{\circ} \mathrm{C}$ and $299^{\circ} \mathrm{C}$.

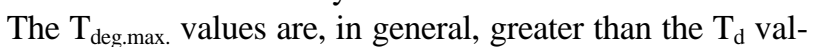
ues for each copolymer, which is as expected since the rate of heating in the TG tests $\left(10^{\circ} \mathrm{C} \cdot \mathrm{min}^{-1}\right)$ was greater than that used in the DSC tests $\left(5^{\circ} \mathrm{C} \cdot \mathrm{min}^{-1}, 2^{\text {nd }}\right.$ run $)$.

When compared with the thermogravimetry results published by SILVA JUNIOR and co-authors (2009) [34], the polymers synthesised in this study show similar mass loss behaviour (weight loss near $100 \%$ and in a single stage), though with lower thermal degradation temperatures. It is attributed to the different molecular masses of the copolymers, as discussed earlier with regard to the DSC results.

Figure 9 shows the TG curves for all of the copolymers synthesised in this study, together with the curves for the respective monomers. These curves show that there is no residual monomer in the copolymers, since no mass loss events characteristic of theses monomers are observed. The TG curves for the copolymers show no mass loss over the temperature range in which the evaporation and degradation of D,L-lactide and glycolide occur. This observation is in agreement with the DSC curves shown in Figures $\mathbf{4}$ to $\mathbf{6}$ (see text for details).

\subsubsection{Nuclear Magnetic Resonance (NMR)}

NMR spectroscopy was used to analyse the composition of the PLGA copolymers. The ratio of D,L-lactide to glycolide was calculated based on the area delimitated by the integral of the D,L-lactide methyl group hydrogens and the area delimitated by the integral of the glycolide methylene group hydrogens [36].
Figures 10 and 11 show, respectively, the ${ }^{1} \mathrm{H}$ NMR spectra obtained for D,L-lactide and glycolide monomers. Table 4 gives the chemical shift values for the $\mathrm{CH}_{3}, \mathrm{CH}_{2}$, and $\mathrm{CH}$ functional groups.

From the results given in Table 4, the methyl group $\left(\mathrm{CH}_{3}\right)$ was adopted as a reference for the D,L-lactide monomer, with a peak of $1.66 \mathrm{ppm}$. With regard to the glycolide, the reference adopted was the peak observed for the methylene group $\left(\mathrm{CH}_{2}\right)$, at $4.99 \mathrm{ppm}$.

Figures 12 to 19 show the ${ }^{1} \mathrm{H}$ NMR spectra obtained for the PLGA copolymers. These spectra were used in order to identify the characteristic functional groups and to determine the ratio between the D,L-lactide and glycolide monomers within the PLGA copolymers. This ratio can be evaluated from Equations 1 and 2 [36]:

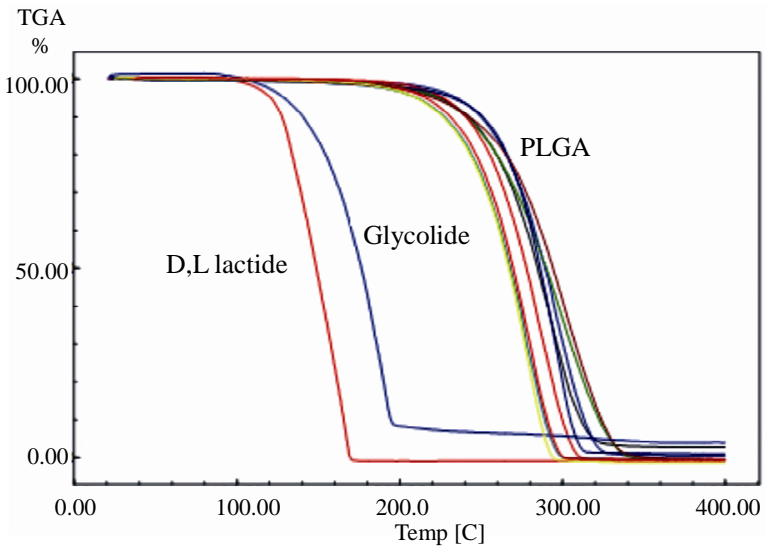

Figure 9. TG curves of D,L-lactide and glycolide monomers and the PLGA copolymers (syntheses $1,2,3,4,5,6,7$ and 8 ). Heating rate of $10^{\circ} \mathrm{C} \cdot \mathrm{min}^{-1}$ from room temperature to $400^{\circ} \mathrm{C}$.

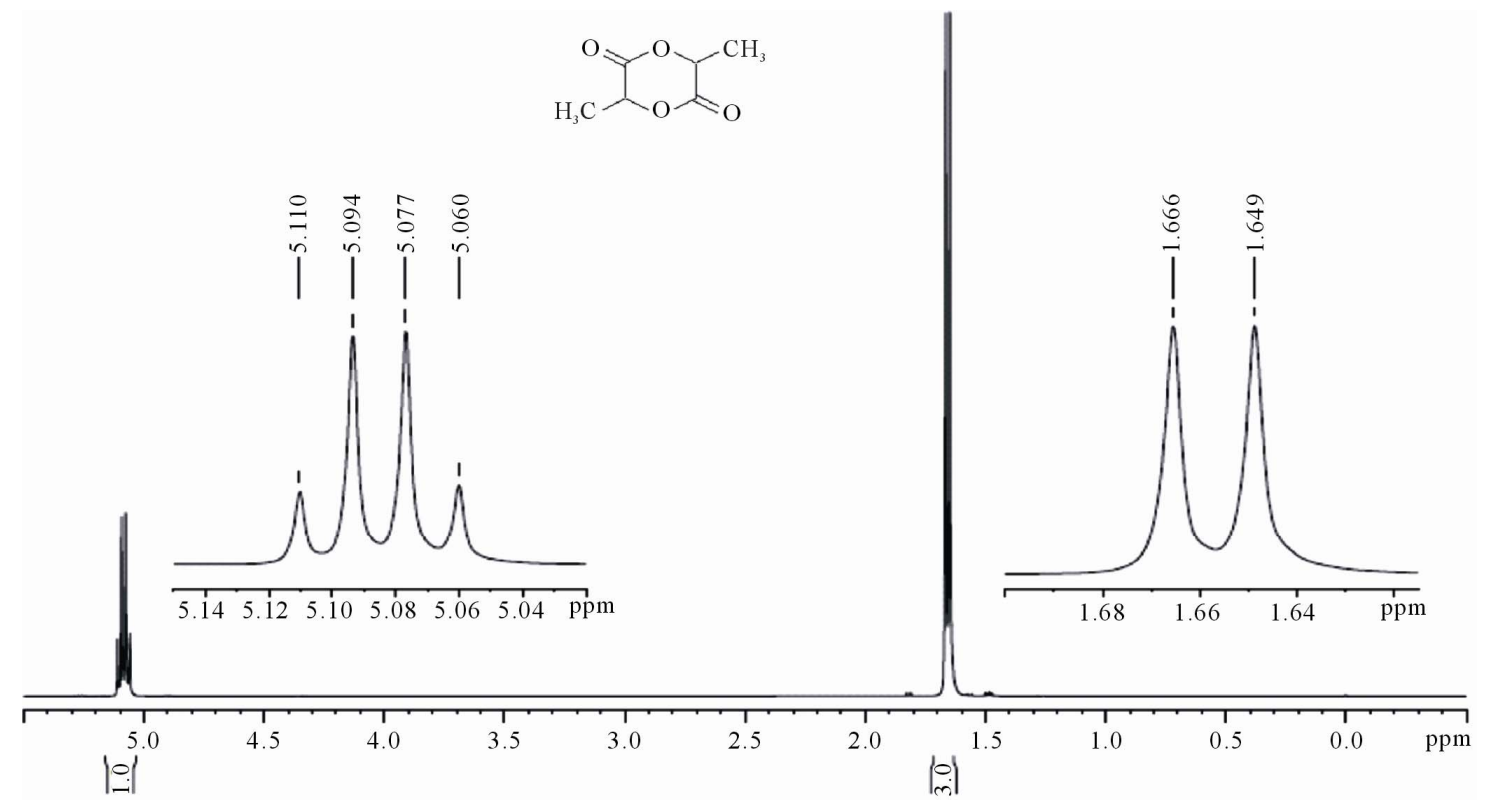

Figure 10. ${ }^{1} \mathrm{H}$ NMR spectrum of D,L-lactide. 


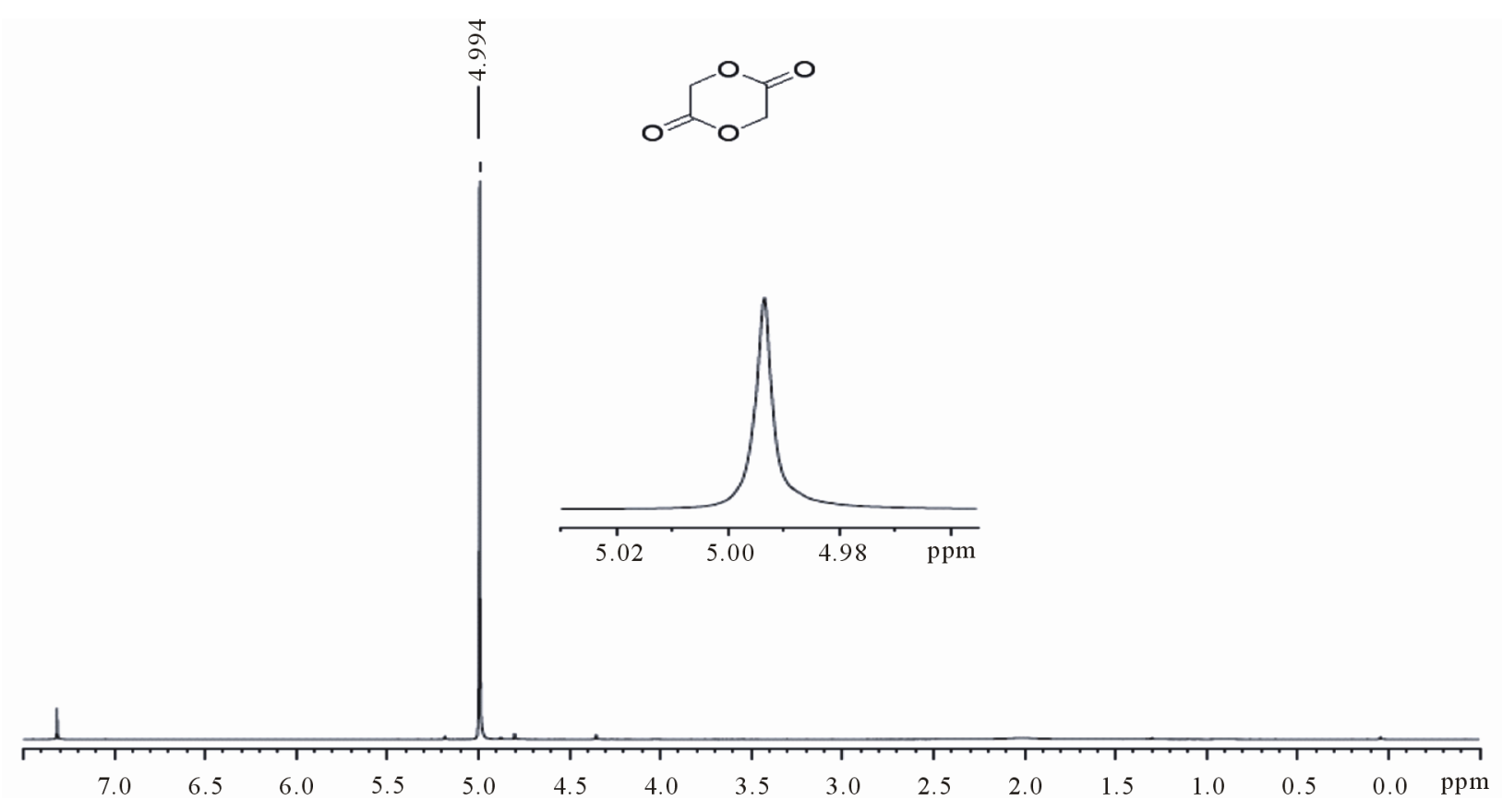

Figure 11. ${ }^{1} \mathrm{H}$ NMR spectrum of glycolide.

Table 4. Chemical shifts obtained from the ${ }^{1} \mathrm{H}$ NMR spectra of D,L-lactide and glycolide monomers.

\begin{tabular}{cccc}
\hline Functinal Group & $\mathbf{C H}_{\mathbf{3}}$ & $\mathbf{C H}_{\mathbf{2}}$ & $\mathbf{C H}$ \\
\hline D,L-lactide $\delta(\mathrm{ppm})$ & 1.66 & N/A & 5.08 \\
Glycolide $\delta(\mathrm{ppm})$ & N/A & 4.99 & N/A \\
\hline
\end{tabular}

\%D,L-lacticle monomer

$=\frac{\left(\mathrm{CH}_{3}\right) \text { integral area } / 3}{\left(\mathrm{CH}_{3}\right) \text { integral area } / 3+\left(\mathrm{CH}_{2}\right) \text { integral area } / 2} \times 100$

$\%$ glycolide monomer

$$
=\frac{\left(\mathrm{CH}_{2}\right) \text { integral area } / 2}{\left(\mathrm{CH}_{3}\right) \text { integral area } / 3+\left(\mathrm{CH}_{2}\right) \text { integral area } / 2} \times 100
$$

No residual signal of monomers are observed in the NMR spectra of the copolymers, which suggests that non-significant quantities of monomers or no monomers at all are present in the final products.

The ${ }^{1} \mathrm{H}$ NMR spectra of the PLGA copolymers obtained in this study agree with those found in the literature [30]. Table 5 shows the chemical shift ranges of the $\mathrm{CH}_{3}, \mathrm{CH}_{2}$ and $\mathrm{CH}$ functional group observed in the spectra presented in Figures 12 to 19.

The theoretical and experimental values of the expected and determined monomer ratios of the PLGA samples are presented in Table 6.

Amongst the syntheses, two of them (4 and 6) show experimental results for the ratio of monomers identical to the theoretical values. For the other syntheses, the lower proportions of the D,L-lactide were $46 \%$ for the
PLGA 50/50 and 63\% for the PLGA 70/30. These results show strong agreement between the real and theoretical ratios. The difference observed in the majority of the syntheses may be due to the absence of the vacuum (syntheses 1 and 2) or an insufficient vacuum when it was used (syntheses 3, 5, 7, and 8). In addition, it is common to find a greater proportion of glycolide in the PLGA copolymer compared to the initial (theoretical) proportion because its reactivity is greater than the reactivity of the D,L-lactide monomer [20].

The PLGA copolymers obtained from syntheses 3, 7 and 9 were also quantitatively analysed by ${ }^{13} \mathrm{C}$ NMR, for comparison with the results obtained from ${ }^{1} \mathrm{H}$ NMR spectroscopy. Table 7 shows the results obtained for the composition of PLGA copolymers based on the quantitative ${ }^{13} \mathrm{C}$ NMR data in comparison with those obtained from the ${ }^{1} \mathrm{H}$ NMR spectra, as well as the expected theoretical values.

As can be seen, the ratio between the monomers in the PLGA determined from the ${ }^{13} \mathrm{C}$ NMR spectra is identical to that found using the ${ }^{1} \mathrm{H}$ NMR spectra, except for the synthesis 3 that is about equal. This result confirms the real proportions of the monomers in the copolymers and validates all of the calculations performed with the ${ }^{1} \mathrm{H}$ NMR data.

Table 5. Chemical shifts ranges observed in the ${ }^{1} H$ NMR spectra of PLGA copolymers.

\begin{tabular}{cccc}
\hline Functinal Group & $\mathbf{C H}_{\mathbf{3}}$ & $\mathbf{C H}_{\mathbf{2}}$ & $\mathbf{C H}$ \\
\hline$\delta(\mathrm{ppm})$ & $1.490-1.687$ & $4.675-4.909$ & $5.157-5.302$ \\
\hline
\end{tabular}




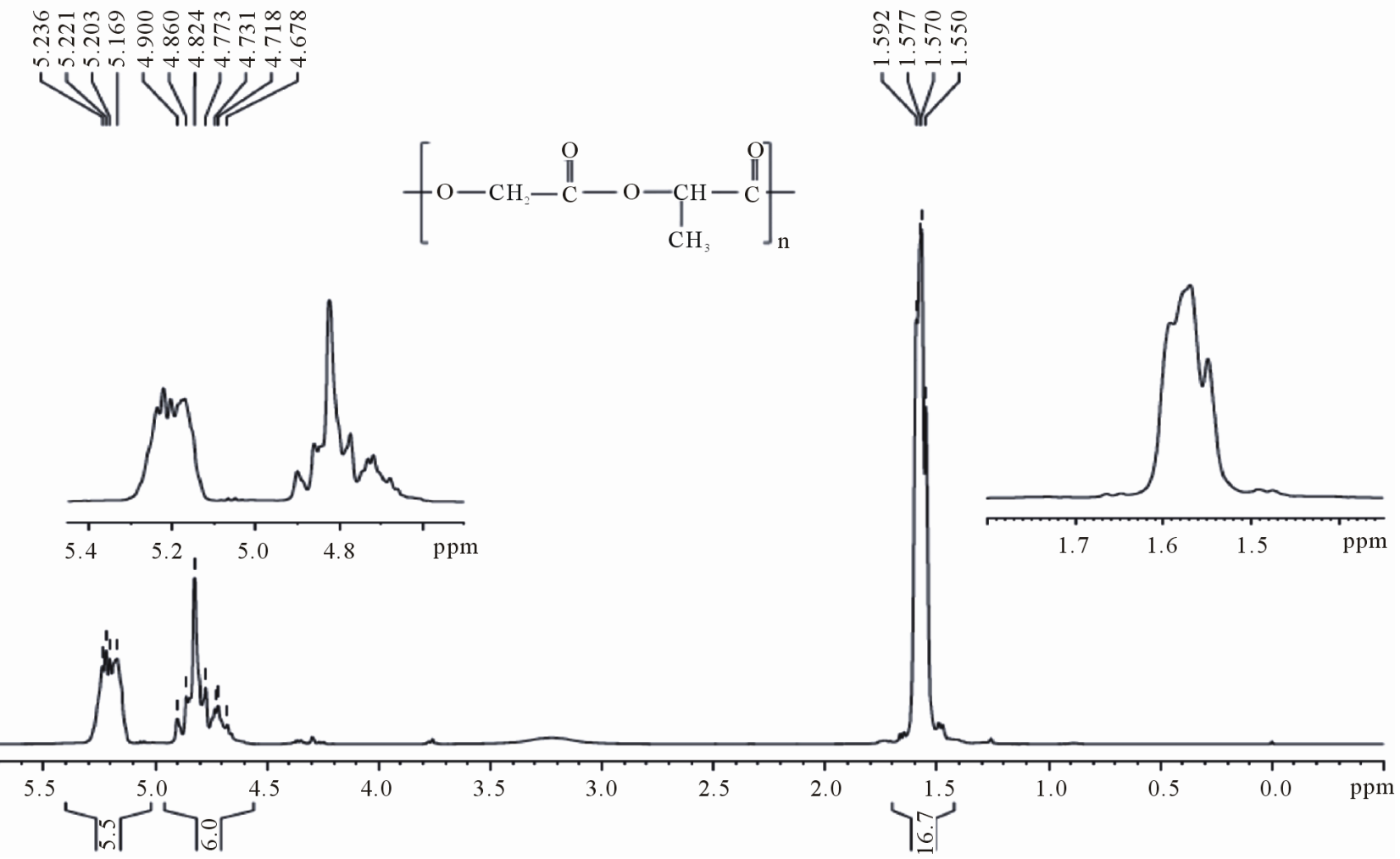

Figure 12. ${ }^{1} \mathrm{H}$ NMR spectrum of PLGA 70/30 (synthesis 1).
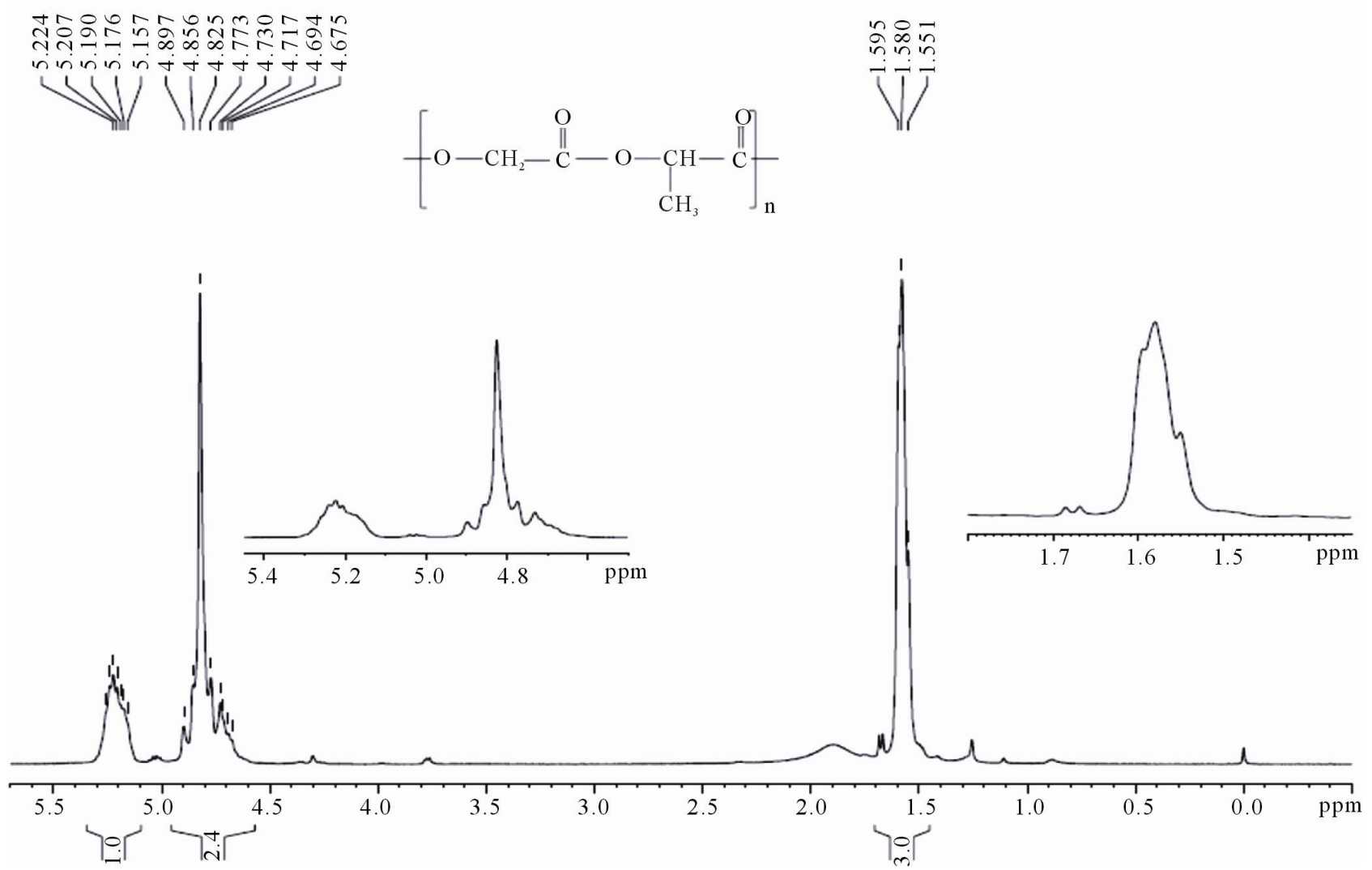

Figure 13. ${ }^{1} \mathrm{H}$ NMR spectrum of PLGA 50/50 (synthesis 2). 


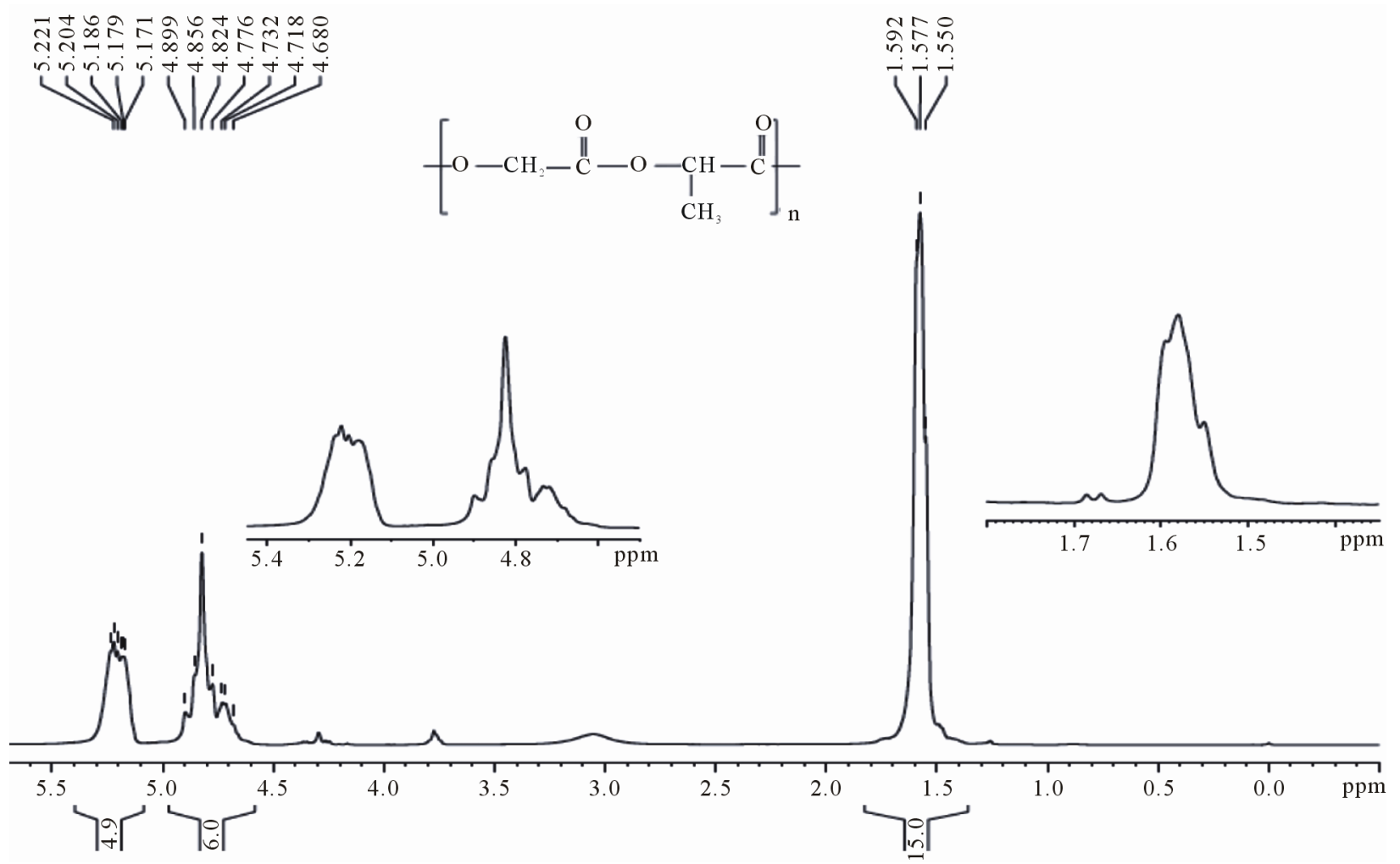

Figure 14. ${ }^{1}$ H NMR spectrum of PLGA 70/30 (synthesis 3).

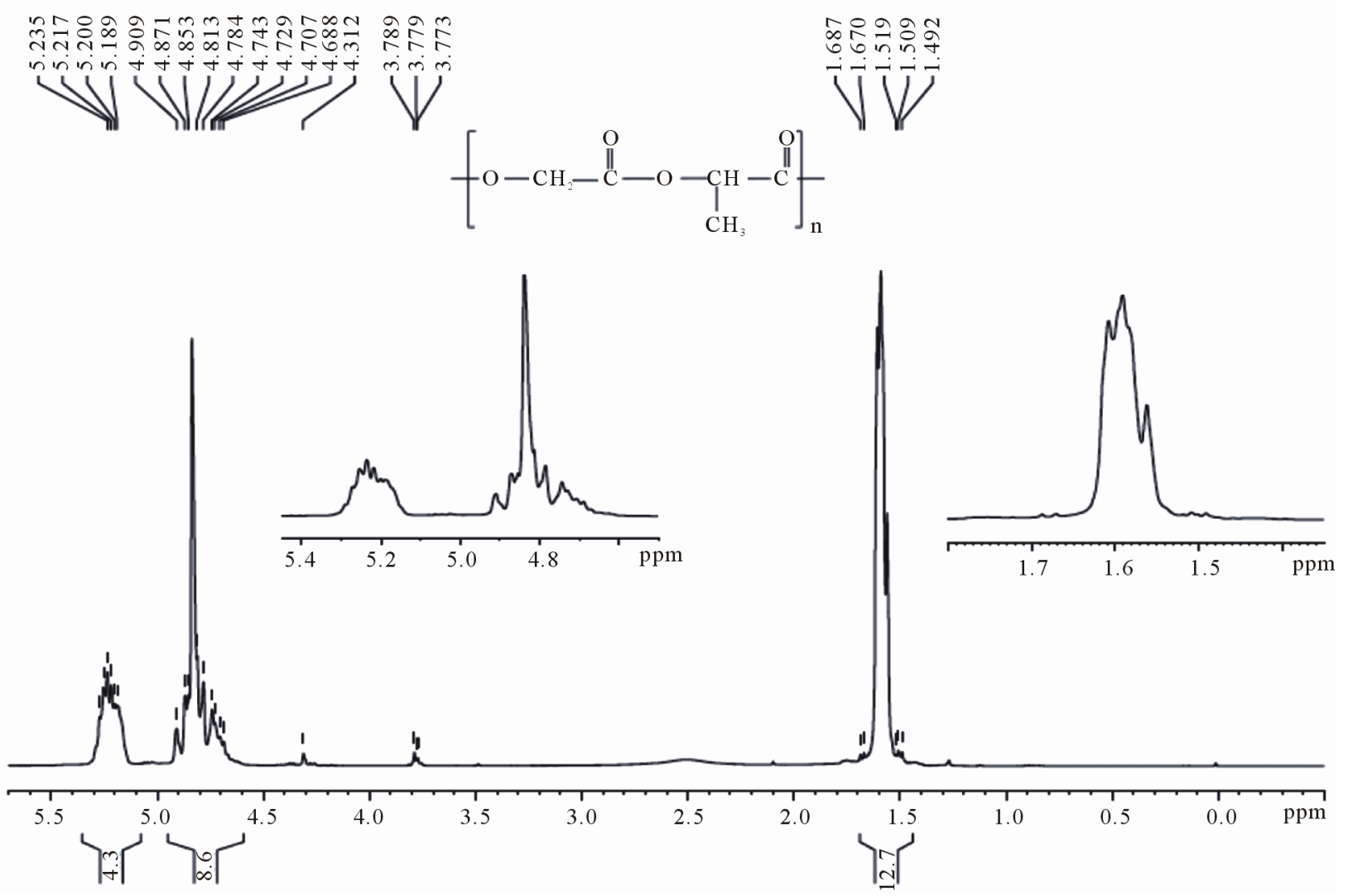

Figure 15. ${ }^{1}$ H NMR spectrum of PLGA 50/50 (synthesis 4). 


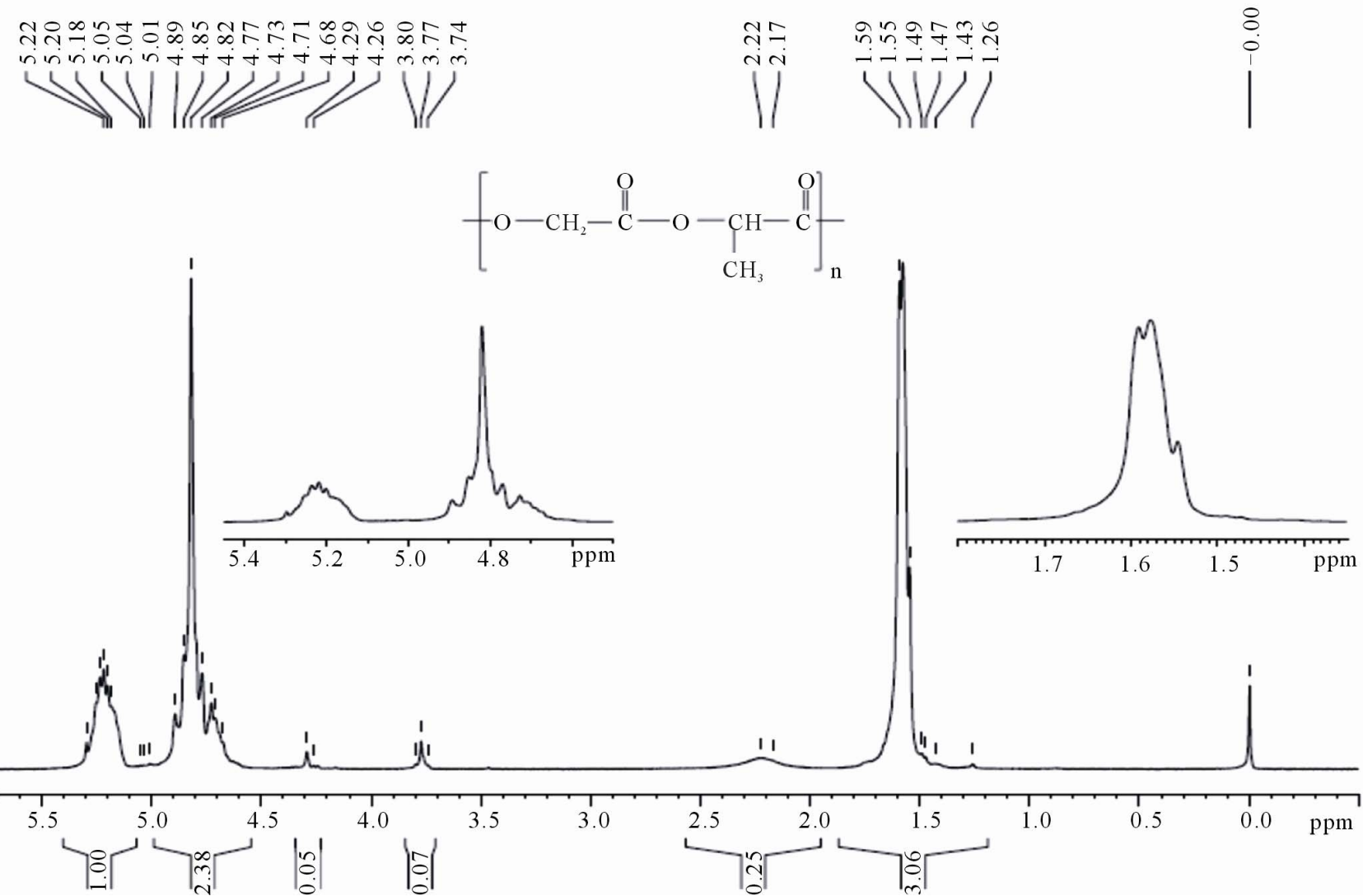

Figure 16. ${ }^{1}$ H NMR spectrum of PLGA 50/50 (synthesis 5).

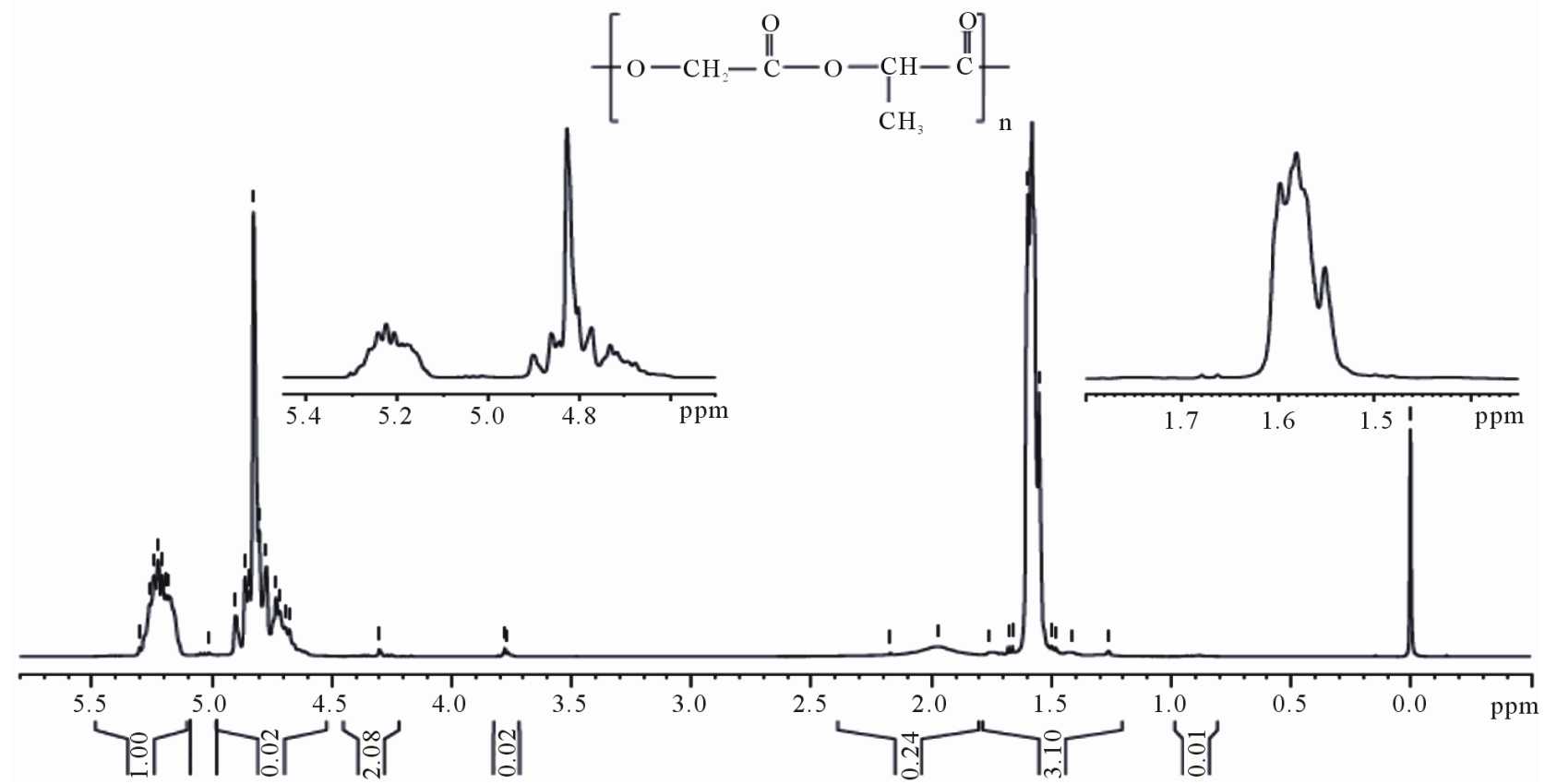

Figure 17. ${ }^{1}$ H NMR spectrum of PLGA 50/50 (synthesis 6). 


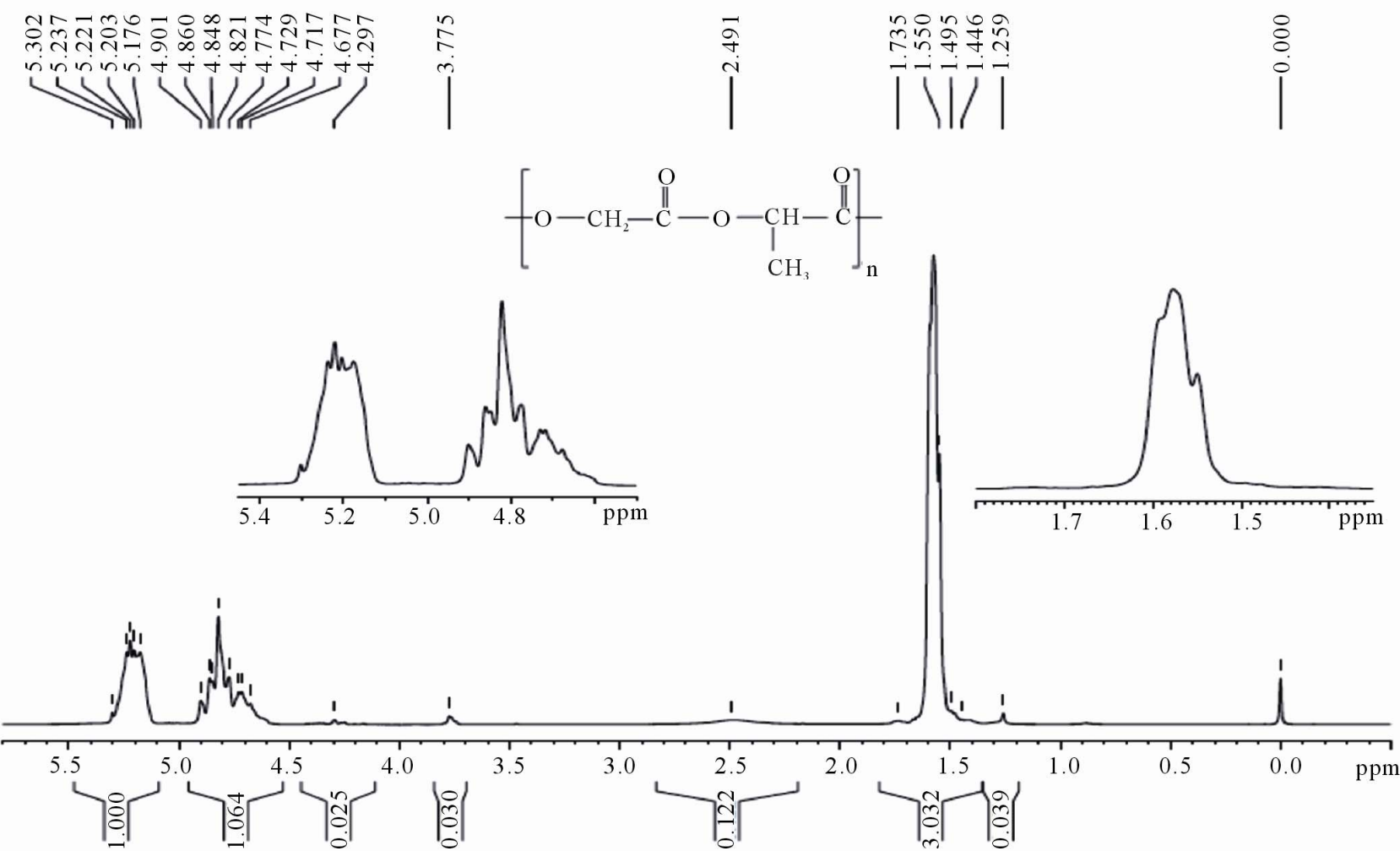

Figure 18. ${ }^{1}$ H NMR spectrum of PLGA 70/30 (synthesis 7).

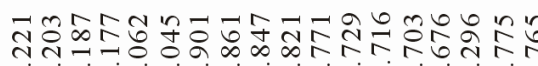

ninin
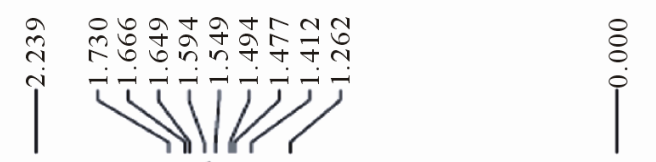

$$
-\mathrm{O}-\mathrm{CH}_{2}-\stackrel{\mathrm{O}}{\mathrm{C}}-\mathrm{O}-\underset{\mathrm{CH}_{3}}{\mathrm{CH}}-\stackrel{\mathrm{I}}{\mathrm{C}}-
$$
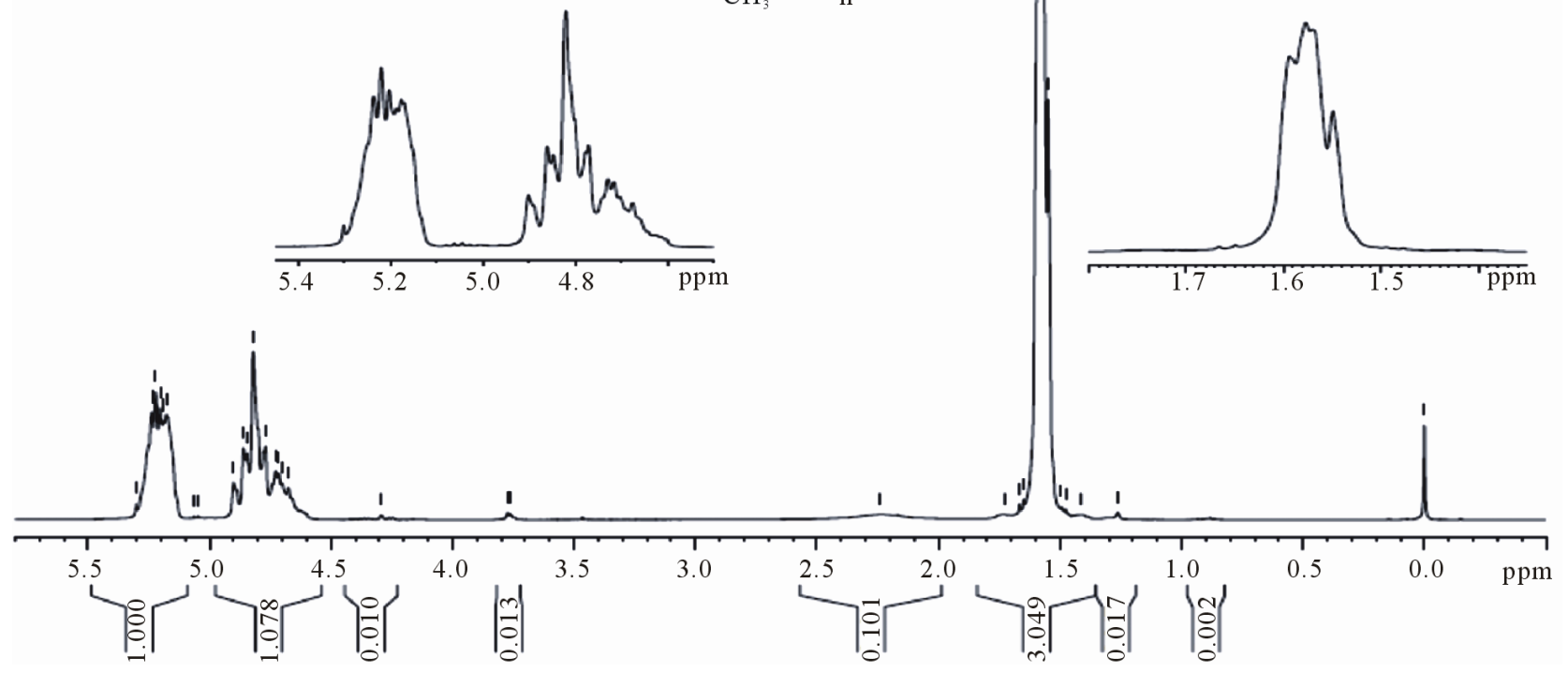

Figure 19. ${ }^{1}$ H NMR spectrum of PLGA 70/30 (synthesis 8). 
Table 6. Expected and determined composition of D,L-lactide and glycolide monomers present in the PLGA copolymers.

\begin{tabular}{cccc}
\hline Synthesis & Theoretical D,L-lactide/Glycolide (\%) & Experimental D,L-lactide (\%) & Experimental Glycolide (\%) \\
\hline $\mathbf{1}$ & $70 / 30$ & 65 & 35 \\
$\mathbf{2}$ & $50 / 50$ & 46 & 54 \\
$\mathbf{3}$ & $70 / 30$ & 63 & 37 \\
$\mathbf{4}$ & $50 / 50$ & 50 & 50 \\
$\mathbf{5}$ & $50 / 50$ & 46 & 54 \\
$\mathbf{6}$ & $50 / 50$ & 50 & 50 \\
$\mathbf{7}$ & $70 / 30$ & 66 & 34 \\
$\mathbf{8}$ & $70 / 30$ & 65 & 35 \\
\hline
\end{tabular}

Table 7. Comparison of the results determined for the real composition of the PLGA copolymers and the theoretical values.

\begin{tabular}{cccc}
\hline \multirow{2}{*}{ Synthesis } & $\begin{array}{c}\text { Theoretical } \\
\text { D,L-lactide/Glycolide (\%) }\end{array}$ & $\begin{array}{c}\text { Experimental } \\
\text { D,L-lactide/Glycolide (\%)- } \mathbf{R M N}{ }^{\mathbf{1}} \mathbf{H}\end{array}$ & $\begin{array}{c}\text { Experimental } \\
\text { D,L-lactide/Glycolide (\%) RMN- }{ }^{\mathbf{1 3}} \mathbf{C}\end{array}$ \\
\hline $\mathbf{3}$ & $70 / 30$ & $63 / 37$ & $62 / 38$ \\
$\mathbf{7}$ & $70 / 30$ & $66 / 34$ & $66 / 34$ \\
$\mathbf{8}$ & $70 / 30$ & $65 / 35$ & $65 / 35$ \\
\hline
\end{tabular}

\subsubsection{Fourier Transform Infrared (FTIR)}

The spectra obtained by FTIR for the D,L-lactide and glycolide monomers are presented in Figures 20 and 21, respectively. One can observe, in both the spectra, strong bands in the region between 1760 and $1750 \mathrm{~cm}^{-1}$, due to stretch of the carbonyl groups present in the two monomers. There are also stretching bands due to asymmetric and symmetric $\mathrm{C}-\mathrm{C}(=\mathrm{O})-\mathrm{O}$ vibrations between 1300 and $1150 \mathrm{~cm}^{-1}$. The bands in these regions are useful in the characterization of esters. The 3500 and $3459 \mathrm{~cm}^{-1}$ bands in the FTIR spectra for lactide and glycolide (Figures 20 and 21, respectively) are attributed to moisture in the sample (OH group). Table $\mathbf{8}$ gives the absorption bands of interest in this study, with their respective attributions.

Figures 22 and $\mathbf{2 3}$ give the spectra of the PLGA copolymers synthesised in this work.

The profile of the spectra presented in Figures 22 and $\mathbf{2 3}$ are practically identical. All of absorption bands presented in Table 8 were found in the spectra for the copolymers presented in these figures. These spectra agree with those given in the literature for PLGA copolymers [38]. The absence of absorption bands between 3600 and $3400 \mathrm{~cm}^{-1}$ in the spectra presented on Figures 22 and 23, characteristic of the hydroxyl group, indicates that the PLGA copolymers are anhydrous.

These FTIR results corroborate the DSC, TG, and NMR results and indicate that the PLGA copolymers have successfully been obtained.

In the attempt to employ FTIR analysis to detect the presence of unreacted monomers, several samples of
PLGA 70/30 were prepared with small quantities of the monomers added in the following proportions: $0.5 \%$ D,L-lactide, and 0.5 and $3 \%$ glycolide. The choice of these proportions was guided by the information that ring opening polymerization produces polymers with about 1 to $3 \%$ residual monomers, according to MIDDLETON and TIPTON (1998) [39].

Figure 24 shows the spectra of the PLGA 70/30 copolymer mixed with $0.5 \% \mathrm{D}$,L-lactide monomer and pure D,L-lactide monomer. The spectra presented in Figure 24 shows an absorption band at $935 \mathrm{~cm}^{-1}$ that is not observed neither in the spectra presented in Figures 22 and 23. However, a high intensity band in $929 \mathrm{~cm}^{-1}$ can be seen in the spectrum for D,L-lactide, Figure 24, very close to that for the PLGA mixture with $0.5 \% \mathrm{D}$,L-lactide. Therefore, it is believed that the D,L-lactide is not present in the obtained PLGA at concentrations above $0.5 \%$.

Regarding the spectra for the mixture of PLGA 70/30 with 0.5 and $3.0 \%$ of the glycolide, it was not possible to detect any significant change with the monomer added to enable the same analysis as achieved for the D,L-lactide monomer. All of the absorption peaks that the glycolide monomer presents overlap those of the PLGA copolymer.

\section{Conclusions}

With regard to the synthesised copolymers, these have a glass transition temperature between $31^{\circ} \mathrm{C}$ and $53^{\circ} \mathrm{C}$ and thermal degradation begins above $240^{\circ} \mathrm{C}$. The mass loss 


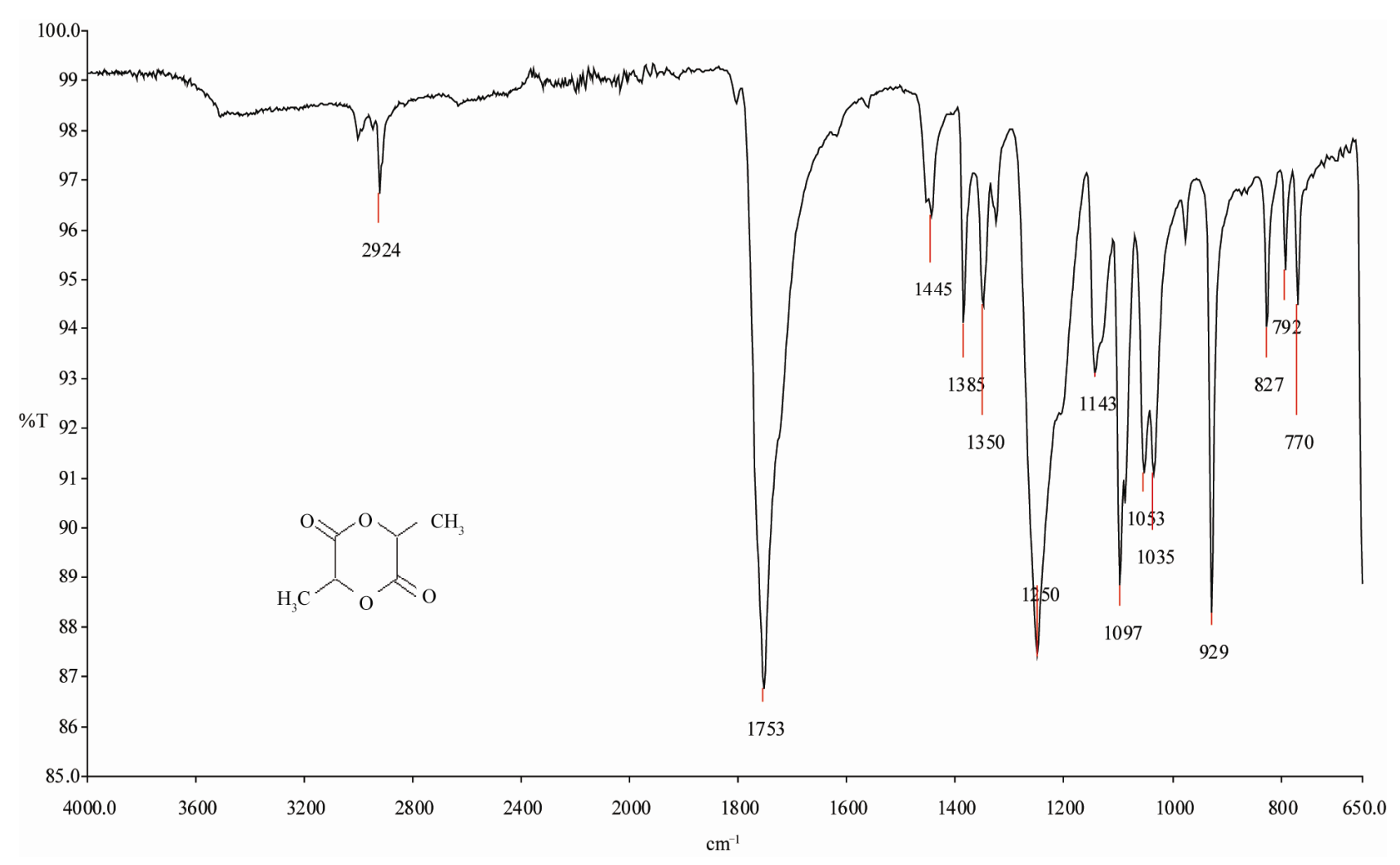

Figure 20. FTIR spectrum for D,L-lactide.

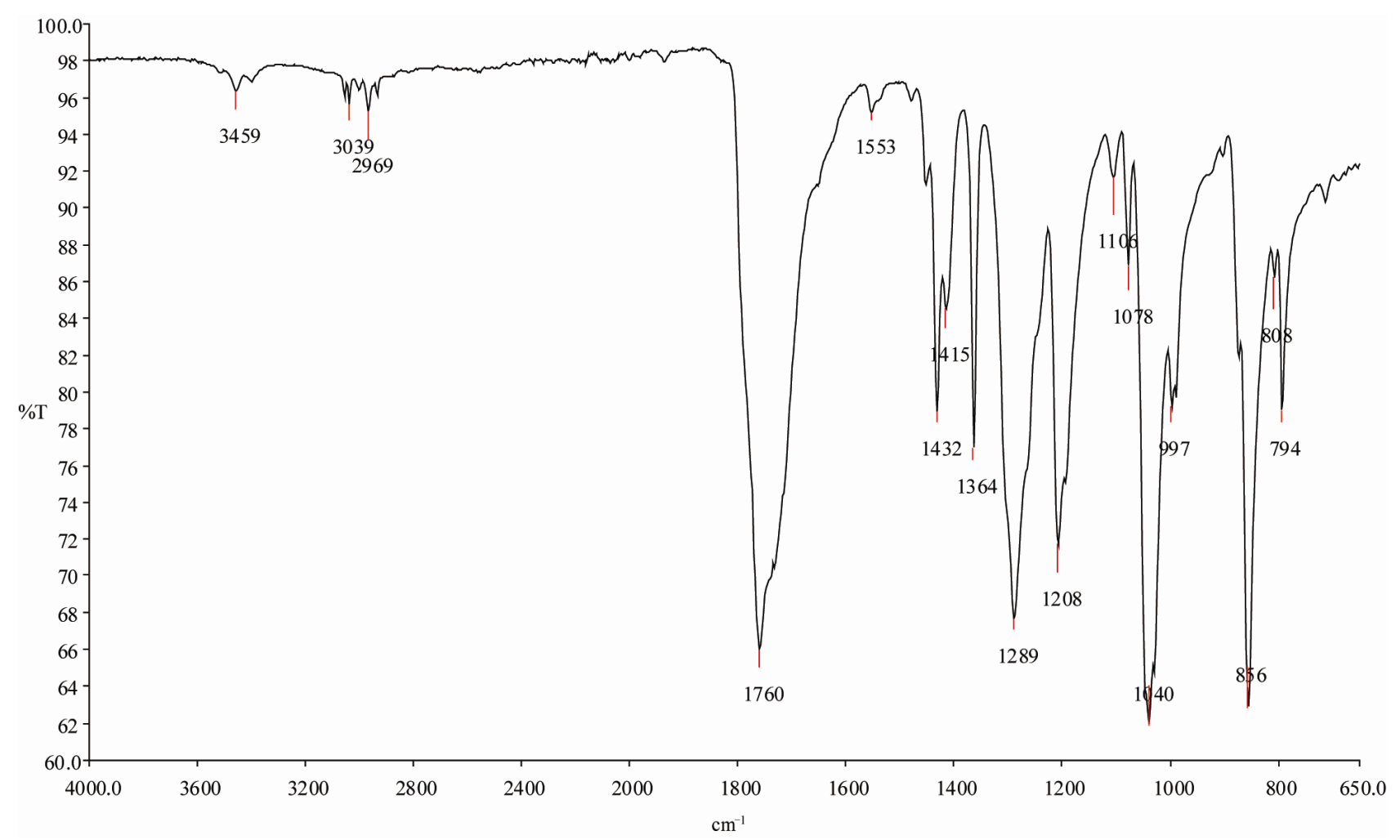

Figure 21. FTIR spectrum for glycolide. 
Table 8. Assignment of the absorption bands observed in the FTIR spectra of D,L-lactide and glycolide.

\begin{tabular}{cc}
\hline Absorption bands (cm $\left.\mathbf{c m}^{-1}\right)$ & Attributions* \\
\hline $3000-2700$ & $\mathrm{CH}, \mathrm{CH}_{3}$ e $\mathrm{CH}_{2}$ (stretching) \\
$1900-1550$ & $\mathrm{C}=\mathrm{O}$ (stretching) \\
$1500-1250$ & $\mathrm{CH}_{3}$ e $\mathrm{CH}_{2}$ (deformation) \\
$1350-1150$ & $\mathrm{CH}_{2}$ e CH (wagging vibration) \\
$1300-1150$ & $\mathrm{C}-\mathrm{O}$ (ester) (stretching) \\
\hline
\end{tabular}

*Attributions according to COLTHUP et al., 1975 [37].

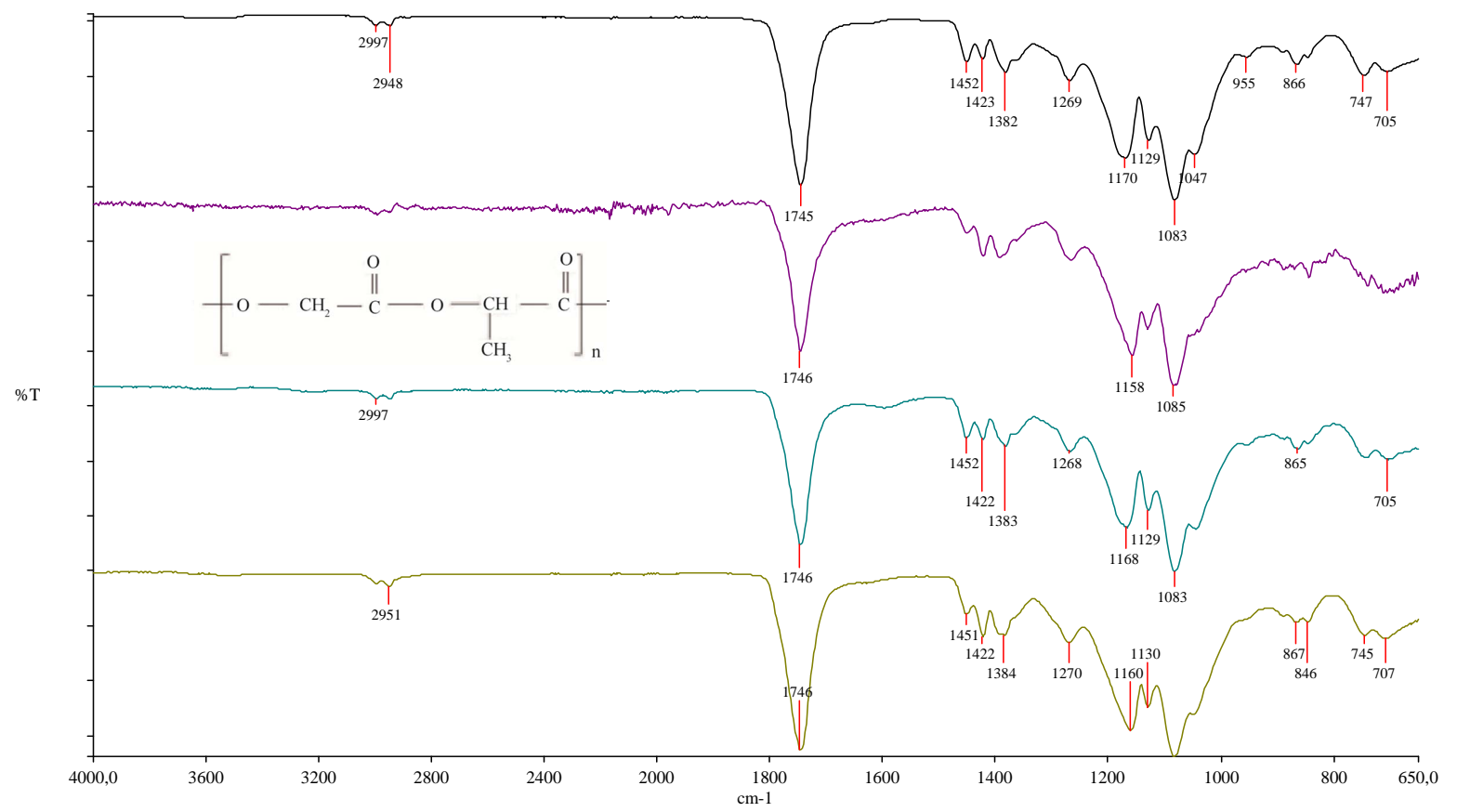

Figure 22. FTIR spectra for PLGA 70/30 (syntheses 1 and 3) and PLGA 50/50 (syntheses 2 and 4).

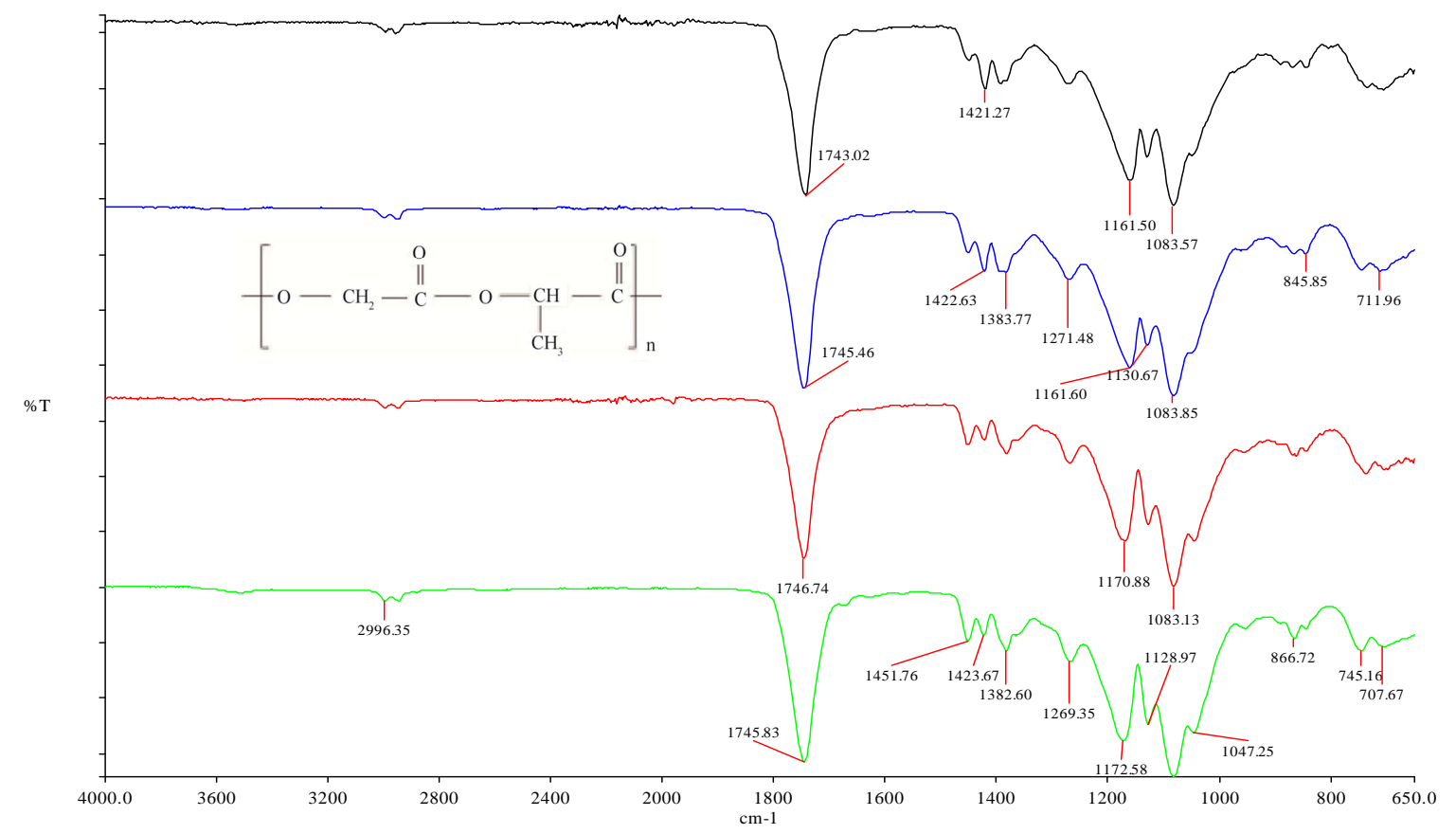

Figure 23. FTIR spectra for PLGA 50/50 (syntheses 5 and 6) and PLGA 70/30 (syntheses 7 and 8). 


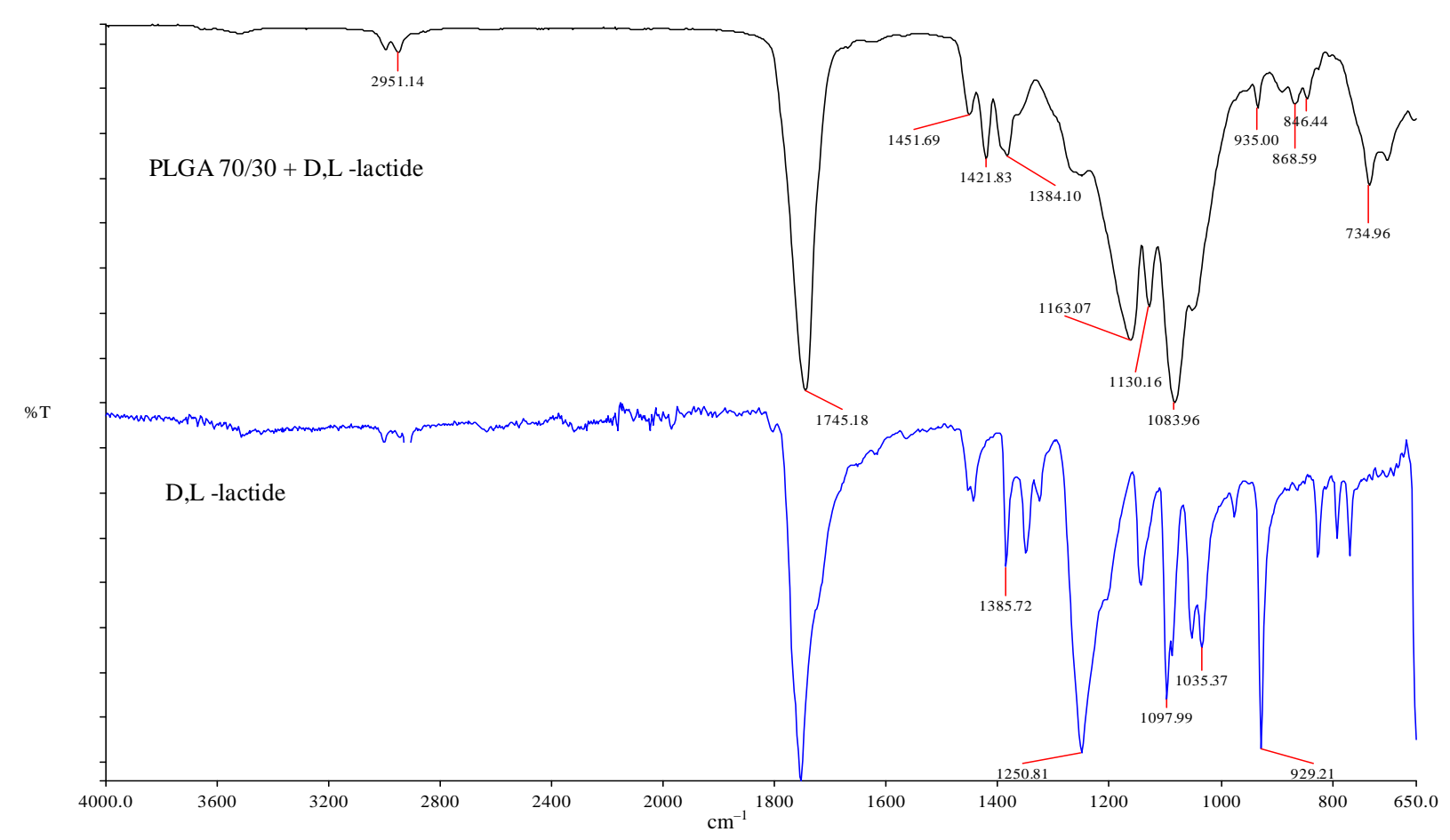

Figure 24. FTIR spectra for the mixture of PLGA 70/30 with $0.5 \%$ D,L-lactide and D,L-lactide monomer.

occurred in a single step, indicating the total degradation of the polymeric chains.

The NMR analysis allowed the copolymer composition to be determined. The spectra obtained for all of the synthesised copolymers showed chemical shifts in accordance with those anticipated in the literature.

With regard to the FTIR analysis, it was possible to determine all of the reference functional groups $(\mathrm{C}=\mathrm{O}$, $\mathrm{C}-\mathrm{O}, \mathrm{CH}_{3}, \mathrm{CH}_{2}$, and $\mathrm{CH}$ ) in the spectra of the synthesised copolymers. The spectra of all of the synthesised copolymers show great similarity and are in agreement with the literature.

To determine the presence of residual monomers in the synthesised copolymers, the results of all of the techniques employed were evaluated together. The DSC technique showed that no endothermic event was detected close to the melting temperatures of the monomers. The thermogravimetry did not present any significant mass loss prior to the onset of copolymer degradation. The NMR analyses did not indicate any significant chemical shift in the spectra for the copolymers that were exactly identical to those in the spectra for the monomers. With regard the FTIR technique, the carbonyl absorption band showed a shift in relation to the monomer bands in all of the copolymer spectra. These results led to the inference that there were no residual monomers in the synthesised copolymers that could be detected by any of the techniques used.

With regard to the special application of FTIR analysis for searching residual monomers, interesting results were obtained when the PLGA mixture was analysed with $0.5 \%$ D,L-lactide monomer. These results demonstrate that this technique can detect residual monomers in these copolymers.

The synthesis route employed consisted of the bulk copolymerization of monomers D,L-lactide and glycolide at $175^{\circ} \mathrm{C}$, with the initiator stannous octoate and co-initiator lauryl alcohol and application of vacuum in reaction medium. The application of vacuum, coupled with adequate stirring, is essential for obtaining good results. It can be concluded that this new route for synthesising PLGA copolymers is successful and the copolymers can be characterised by FTIR, NMR, DSC, and TG analysis.

\section{Acknowledgements}

Cynthia D. C. Erbetta acknowledges FAPEMIG for supporting grants. Authors gratefully acknowledge the support by FAPEMIG, CAPES and CNPQ.

\section{REFERENCES}

[1] I. Y. Galaev and B. Mattiasson, "Smart Polymers and What They Could Do in Biotechnology and Medicine," Trends in Biotechnology, Vol. 17, No. 8, 1999, pp. 335340. doi:10.1016/S0167-7799(99)01345-1

[2] O. Pillail and R. Panchagnula, "Polymers in Drug Delivery,” Current Opinion in Chemical Biology, Vol. 5, No. 4, 2001, pp. 447-451. doi:10.1016/S1367-5931(00)00227-1

[3] S. Li, "Hydrolytic Degradation Characteristics of Aliphatic Polyesters Derived from Lactic and Glycolic Ac- 
ids,” Journal of Biomedical Materials Research, Vol. 48, No. 3, 1999, pp. 342-53. doi:10.1002/(SICI)1097-4636(1999)48:3<342::AID-JBM 20>3.0.CO;2-7

[4] A. S. Hoffman, "Hydrogels for Biomedical Application," Advanced Drug Delivery Reviews, Vol. 54, No. 1, 2002, pp. 3-12. doi:10.1016/S0169-409X(01)00239-3

[5] R. Chera and R. Rustgi, "Biodegradable Polymers,” Progress in Polymer Science, Vol. 23, No. 7, 1998, pp. 12731335. doi:10.1016/S0079-6700(97)00039-7

[6] O. Seigo, "Application of Superabsorbent Polymers in Japanese Agriculture and Greening, Gels Handbook,” Academic Press, Waltham, 2001.

[7] R. Langer and N. A. Peppas, "Advances in Biomaterials, Drug Delivery, and Bionanotechnology," AlChE Journal, Vol. 49, No. 12, 2003, pp. 2990-3006. doi:10.1002/aic.690491202

[8] M. Chasin and R. Langer, "Biodegradable Polymers as Drug Delivery Systems,” McGraw-Hill, New York, 1990.

[9] C. E. Soma, C. Dubernet, D. Bentolila, S. Benita and P. Couvreur, "Reversion of Multidrug Resistance by Co-Encapsulation of Doxorubicin and Cyclosporin A in Polyalkylcyanoacrylate Nanoparticles,” Biomaterials, Vol. 21, No. 1, 2000, pp. 1-7. doi:10.1016/S0142-9612(99)00125-8

[10] R. A. Jain, "The Manufacturing Techniques of Various Drug Loaded Biodegradable Poly(Lactide-Co-Glycolide) (PLGA) Devices,” Biomaterials, Vol. 21, No. 23, 2000, pp. 2475-2490. doi:10.1016/S0142-9612(00)00115-0

[11] V. Michel, "Polymeric Biomaterials: Strategies of the Past vs. Strategies of the Future," Progress in Polymer Science, Vol. 32, No. 8-9, 2007, pp. 755-761. doi:10.1016/j.progpolymsci.2007.05.006

[12] L. Xiaoling and R. J. Haskara, "Design of Controlled Release Drug Delivery Systems,” MacGraw-Hill, New York, 2006.

[13] N. Angelova and D. Hunkeler, "Rationalizing the Design of Polymeric Biomaterials,” Trends in Biotechnology, Vol. 17, No. 10, 1999, pp. 409-421. doi:10.1016/S0167-7799(99)01356-6

[14] M. M. M. Elnashar, "Review Article: Immobilized Molecules Using Biomaterials and Nanobiotechnology,” Journal of Biomaterials and Nanobiotechnology, Vol. 1, No. 1, 2010, pp. 61-77. doi:10.4236/jbnb.2010.11008

[15] A. Q. Soares, L. F. Oliveira, D. Rabelo and A. R. Souza, "Polímeros Biodegradáveis: Novas Perspectivas Para as Ciências Farmacêuticas,” Revista Eletrônica de Farmácia, Vol. 2, No. 2, 2005, pp. 202-205.

[16] M. L. Hans and A. M. Lowman, "Biodegradable Nanoparticles for Drug Delivery and Targeting," Current Opinion in Solid State and Materials Science, Vol. 6, No. 4, 2002, pp. 319-327. doi:10.1016/S1359-0286(02)00117-1

[17] Q. Cai, G. Shi, J. Bei and S. Wang, "Enzymatic Degradation Behavior and Mechanism of Poly(Lactide-Co-Glycolide) Foams by Trypsin,” International Journal of Pharmaceutics, Vol. 24, No. 4, 2003, pp. 629-638.

[18] J. Lunt, "Large-Scale Production, Properties and Commercial Applications of Polylactic Acid Polymers," Polymer Degradation and Stability, Vol. 59, No. 1-3, 1998, pp.

\section{5-152. doi:10.1016/S0141-3910(97)00148-1}

[19] H. Fukuzaki, M. Yoshida, M. Asano and M. Kumakura, "Synthesis of copoly(D,L-Lactic Acid) with Relatively Low Molecular Weight and in Vivo Degradation," European Polymer Journal, Vol. 25, No. 10, 1989, pp. 10191026. doi:10.1016/0014-3057(89)90131-6

[20] D. K. Gilding and A. M. Reed, "Biodegradable Polymers for Use in Surgery Polyglycolid/Poly(Lactic Acid) Homo and Copolymers," Polymer, Vol. 20, No. 12, 1979, pp. 1459-1464. doi:10.1016/0032-3861(79)90009-0

[21] D. Bendix, "Chemical Synthesis of Polylactide and Its Copolymers for Medical Applications,” Polymer Degradation and Stability, Vol. 59, No. 1-3, 1998, pp. 129-135. doi:10.1016/S0141-3910(97)00149-3

[22] P. B. Deasy, M. P. Finan and M. J. Meegan, "Preparation and Characterization of Lactic/Glycolic Acid Polymers and Copolymers," Journal of Microencapsulation, Vol. 6, No. 3, 1989, pp. 369-378.

[23] C. Jéôme and P. Lecomte, "Recent Advances in the Synthesis of Aliphatic Polyesters by Ring-Opening Polymerization," Advanced Drug Delivery Reviews, Vol. 60, No. 9, 2008, pp. 1056-1076. doi:10.1016/j.addr.2008.02.008

[24] B. D. Ratner and A. S. Hoffman, "Biomaterials ScienceAn Introduction to Materials in Medicine,” Elsevier Academic Press, Waltham, 1996.

[25] M. J. Blanco-Prieto, E. Fattal, F. Puisieux and P. Couvreur, "The Multiple Emulsion as a Common Step for the Design of Polymeric Microparticles,” In: J. L. Grossiord and M. Seiller, Eds., Multiple Emulsions: Structure, Properties and Applications, Éditions de Santé, Paris, 1998, pp. 397-435.

[26] D. H Lewis, "Controlled Release of Bioactive Agents from Lactide/Glycolide Polymers,” In: M. Chasin and R. Langer, Eds., Biodegradable Polymers as Drug Delivery Systems, Marcel Dekker, New York, 1990, pp. 1-41.

[27] S. L. Fialho, M. G. B. Rego, J. A. Cardillo, R. C. Siqueira, R. Jorge and A. S. Cunha Jr., "Implantes Biodegradáveis Destinados à Administração Intra-Ocular,” Arquivos Brasileiros de Oftalmologia, Vol. 66, No. 6, 2003, pp. 891896. doi:10.1590/S0004-27492003000700029

[28] A. Merkli, C. Tabatabay, R. Gurny and J. Heller, "Biodegradable Polymers for the Controlled Release of Ocular Drugs," Progress in Polymer Science, Vol. 23, No. 3, 1998, pp. 563-580. doi:10.1016/S0079-6700(97)00048-8

[29] K. A. Athanasiou, G. G. Niederauer and C. M. Agrawal, "Sterilization, Toxicity, Biocompatibility and Clinical Applications of Polylactic Acid/Polyglycolic Acid Copolymers”, Biomaterials, Vol. 17, No. 2, 1996, pp. 93-102. doi:10.1016/0142-9612(96)85754-1

[30] M. Kiremitçi-Gümüsderelioglu and G. Deniz, "Synthesis, Characterization and in Vitro Degradation of Poly(D,LLactide)/Poly(D,L-Lactide-Co-Glycolide),” Turkish Journal of Chemistry, Vol. 23, No. 2, 1999, pp. 153-161.

[31] X. Kaitian, A. Kozluca, E. B. Denkbas and E. Piskin, "Poly(D,L-Lactic acid) Homopolymers: Synthesis and Characterization,” Turkish Journal of Chemistry, Vol. 20, No. 1, 1996, pp. 43-53. 
[32] E. Jabbari, E. Xuezhong, "Synthesis and Characterization of Bioresorbable in Situ Crosslinkable Ultra Low Molecular Weight Poly(Lactide) Macromere," Journal of Materials Science: Materials in Medicine, Vol. 19, No. 1, 2008, pp. 311-317. doi:10.1007/s10856-006-0020-2

[33] V. Kumar and G. S. Banker, "Chemically-Modified Cellulosic Polymers,” Drug Development and Industrial Pharmacy, Vol. 19, No. 1, 1993, pp. 1-31.

[34] A. A. Silva Jr., J. R. Matos, T. P. Formariz, G. Rossanezi, M. V. Scarpa, E. S. do Egito and A. G. Oliveira, "Thermal Behavior and Stability of Biodegradable Spray-Dried Microparticles Containing Triamcinolone,” International Journal of Pharmaceutics, Vol. 368, No. 1-2, 2009, pp. 45-55.

[35] R. Lindhardt, "Polímeros Biodegradáveis Para Liberação
Controlada de Droga,” Springer-Verlag, Now York, 1998.

[36] A. G. Hausberger and P. P. DeLuca, "Characterization of Biodegradable Poly(D,L-Lactide-Co-Glycolide) Polymers and Microparticles,” Journal of Pharmaceutical and Biomedical Analysis, Vol. 13, No. 6, 1995, pp. 747-760. doi:10.1016/0731-7085(95)01276-Q

[37] N. B. Colthup, L. H. Daly and S. E. Wiberley, "Introduction to Infrared and Raman Spectroscopy," 2nd Edition, Academic Press, New York, 1975.

[38] D. O. Hummel, "Atlas of Polymer and Plastics Analysis," Wiley, New York, 2001.

[39] J. C. Middleton and A. J. Tipton, "Synthetic Biodegradable Polymers as Medical Devices," Medical Plastics and Biomaterials Magazine, Vol. 3-4, 1998, pp. 31-38. 